\title{
Nipah Virus Envelope-Pseudotyped Lentiviruses Efficiently Target ephrinB2-Positive Stem Cell Populations In Vitro and Bypass the Liver Sink When Administered In Vivo
}

\author{
Karina Palomares, ${ }^{a}$ Frederic Vigant, ${ }^{a}$ Ben Van Handel, ${ }^{c}$ Olivier Pernet, ${ }^{a}$ Kelechi Chikere, ${ }^{a}$ Patrick Hong, ${ }^{\text {a }}$ Sean P. Sherman, ${ }^{b}$ \\ Michaela Patterson, ${ }^{c}$ Dong Sung An, ${ }^{d, e, i}$ William E. Lowry, ${ }^{b, c, g, h}$ Hanna K. A. Mikkola, ${ }^{b, c, g, h}$ Kouki Morizono, ${ }^{e, i}$ April D. Pyle, ${ }^{a, b, g, h}$ \\ Benhur Lee ${ }^{a, f, h, i}$
}

Department of Microbiology, Immunology and Molecular Genetics, ${ }^{a}$ Molecular Biology Institute, ${ }^{b}$ Department of Molecular, Cell, and Developmental Biology, ${ }^{c}$ School of Nursing, ${ }^{\mathrm{d}}$ Department of Medicine, Division of Hematology and Oncology, ${ }^{e}$ Department of Pathology and Laboratory Medicine, ${ }^{f}$ Jonnson Comprehensive Cancer Center, ${ }^{9}$ Eli and Edythe Broad Center of Regenerative Medicine and Stem Cell Research, ${ }^{\text {h }}$ and AIDS Institute, David Geffen School of Medicine, University of California, Los Angeles, California, USA

Sophisticated retargeting systems for lentiviral vectors have been developed in recent years. Most seek to suppress the viral envelope's natural tropism while modifying the receptor-binding domain such that its tropism is determined by the specificity of the engineered ligand-binding motif. Here we took advantage of the natural tropism of Nipah virus (NiV), whose attachment envelope glycoprotein has picomolar affinity for ephrinB2, a molecule proposed as a molecular marker of "stemness" (present on embryonic, hematopoietic, and neural stem cells) as well as being implicated in tumorigenesis of specific cancers. NiV entry requires both the fusion (F) and attachment $(\mathrm{G})$ glycoproteins. Truncation of the NiV-F cytoplasmic tail (T5F) alone, combined with full-length NiV-G, resulted in optimal titers of NiV-pseudotyped particles (NiVpp) $\left(\sim 10^{6} \mathrm{IU} / \mathrm{ml}\right)$, even without ultracentrifugation. To further enhance the infectivity of NiVpp, we engineered a hyperfusogenic NiV-F protein lacking an N-linked glycosylation site ( $\mathrm{T} 5 \mathrm{~F} \Delta \mathrm{N} 3)$. T5F $\Delta \mathrm{N} 3 /$ wt G particles exhibited enhanced infectivity on less permissive cell lines and efficiently targeted ephrinB2 ${ }^{+}$cells even in a 1,000-fold excess of ephrinB2-negative cells, all without any loss of specificity, as entry was abrogated by soluble ephrinB2. NiVpp also transduced human embryonic, hematopoietic, and neural stem cell populations in an ephrinB2-dependent manner. Finally, intravenous administration of the luciferase reporter NiVpp-T5F $\Delta$ N3/G to mice resulted in signals being detected in the spleen and lung but not in the liver. Bypassing the liver sink is a critical barrier for targeted gene therapy. The extraordinary specificity of $\mathrm{NiV}-\mathrm{G}$ for ephrinB2 holds promise for targeting specific ephrinB2 ${ }^{+}$populations in vivo or in vitro.

entiviruses are common vectors used in gene therapy because they can transduce nondividing cells and offer stable integration into a target cell's genome. The host range can be altered by pseudotyping with glycoproteins derived from other enveloped viruses. The most commonly used glycoprotein $(G)$ is that of vesicular stomatitis virus (VSV), which has great stability in the vector particle, allowing concentration to high titers, and also has a ubiquitous host cell receptor allowing transduction of most cell types $(1,2)$. VSV-G-pseudotyped particles (VSV-Gpp) have become the standard for evaluating the efficiency of transduction by other viral envelope pseudotypes. However, VSV-Gpp cannot be targeted to specific populations of cells, which is necessary for in vivo gene transfer applications.

More specific cell targeting can be achieved by pseudotyping with envelopes modified in various ways that allow for retargeting via some ligand-specific domain $(3,4)$. Measles virus $(\mathrm{MeV})$ glycoproteins (Edmonston strain) can also be pseudotyped efficiently onto a lentiviral vector, but only when the cytoplasmic tails of both envelope glycoproteins, the hemagglutinin $(\mathrm{H})$ and fusion $(\mathrm{F})$ proteins, are truncated. MeV Edmonston uses CD46 and/or SLAM as an entry receptor. In humans, CD46 is expressed on all nucleated cells (5), and thus the natural tropism of $\mathrm{MeV}$ does not offer $\mathrm{MeVpp}$ any specific targeting advantage in vivo. However, ex vivo, $\mathrm{MeVpp}$ can transduce unstimulated primary human B and T cells that are relatively resistant to even VSV-Gpp transduction, suggesting that MeVpp are at least useful as an experimental tool $(6,7)$.
More recently, the unique features of $\mathrm{MeV}$ entry have allowed for some innovations that have attracted considerable interest (810). Measles virus is a member of the Morbillivirus genus in the Paramyxovirinae subfamily of paramyxoviruses. Paramyxovirus entry requires the coordinated action of both the fusion $(\mathrm{F})$ and attachment (designated $\mathrm{HN}, \mathrm{H}$, or $\mathrm{G}$, depending on the receptorbinding properties) glycoproteins; receptor binding to the viral attachment glycoprotein induces an allosteric change that triggers $\mathrm{F}$ to undergo a conformational cascade that results in virus-cell membrane fusion and entry (11-13). Morbillivirus is one of only two genera of paramyxoviruses that use protein-based receptors; the others use ubiquitous glycan-based receptors such as sialic acids. The aforementioned innovation takes advantage of the wealth of structure-function information that has not only mapped the receptor-binding sites on $\mathrm{MeV}-\mathrm{H}$ but also characterized key features of the ensuing receptor-binding-triggered fusion cascade $(13,14)$. Thus, by mutating the native receptor-binding sites on $\mathrm{MeV}-\mathrm{H}$ and appending to the $\mathrm{C}$ terminus of the mutated

Received 3 August 2012 Accepted 12 November 2012

Published ahead of print 28 November 2012

Address correspondence to Benhur Lee, bleebhl@ucla.edu.

Copyright @ 2013, American Society for Microbiology. All Rights Reserved.

doi:10.1128/JVI.02032-12 
$\mathrm{MeV}-\mathrm{H}$ protein (a type II transmembrane protein) the singlechain variable fragment ( $\mathrm{scFv}$ ) from a monoclonal antibody recognizing specific cell surface antigens, $\mathrm{MeVpp}$ can successfully be retargeted, at least in vitro, to neurons, endothelial cells, and hematopoietic progenitors (15). Nevertheless, the development of $\mathrm{MeVpp}$ as an in vivo-targeted human gene therapy vector is limited by the widespread presence of preexisting neutralizing antibodies in the vast majority of the human population that have received $\mathrm{MeV}$ vaccination.

Nipah $(\mathrm{NiV})$ and Hendra $(\mathrm{HeV})$ viruses belong to the only other genus (Henipavirus) of paramyxoviruses that use proteinbased receptors. A recent study showed that the full-length Nipah virus envelope glycoproteins could be pseudotyped onto a lentiviral vector and mediate entry into various cell lines, although infectious titers were not determined (16). For NiV, the attachment glycoprotein, $\mathrm{NiV}-\mathrm{G}$, functions in recognition of the receptor. As for $\mathrm{MeV}$, binding of the receptor to NiV-G triggers a series of conformational changes that eventually lead to NiV-F triggering and virus-cell membrane fusion (reviewed in reference12). Henipaviruses use ephrinB2 as the primary receptor and, somewhat less efficiently, ephrinB3 as an alternate receptor (17-19). The remarkably high affinity of NiV-G for ephrinB2 $\left(K_{d}\right.$ [dissociation constant] $=0.06 \mathrm{nM})(19)$ suggests that NiV-pseudotyped particles (NiVpp) can be targeted efficiently and specifically to ephrinB2 ${ }^{+}$cells. Thus, instead of retargeting strategies, we sought to exploit the natural tropism of $\mathrm{NiV}$ for specific targeting of primary ephrinB2-expressing cell types that are of significant biological and clinical interest to the gene-targeting community.

Ephrin-eph receptor-ligand pairs are membrane-associated receptor tyrosine kinases (RTKs) with well-established roles in many developmental processes; they regulate cell boundaries during tissue and bone formation, as well as providing guidance cues during neurogenesis and angiogenesis (20). EphrinB2-ephB4 interactions have been implicated strongly in tumor angiogenesis, migration, and invasion (21). In addition, ephrinB2 has been proposed as a molecular marker of "stemness," being expressed on murine embryonic stem cells (ESCs), hematopoietic stem cells (HSCs), and neural stem cells (NSCs) (22). Thus, the ability to target lentiviral vectors specifically to ephrinB2 ${ }^{+}$cells may be useful for studying specific stem cell populations or for disrupting tumorigenesis in cases where the ephrinB2-ephB4 axis plays a critical role (20).

Here we systematically investigated which modifications to the cytoplasmic tails of the NiV glycoproteins could best enhance the efficiency of pseudotyping onto lentiviral particles. We found that efficient functional pseudotyping with the $\mathrm{NiV}$ envelope requires truncation of only the F protein cytoplasmic tail, while full-length $\mathrm{NiV}-\mathrm{G}$ can be used. Unlike the case for MeVpp, full-length and truncated $\mathrm{F}$ proteins were equally incorporated into NiVpp, indicating that the requirements for functional lentiviral pseudotyping differ between $\mathrm{MeV}$ and $\mathrm{NiV}$. NiVpp specifically targeted ephrinB2 ${ }^{+}$cells in a 1,000-fold excess of ephrinB2-negative cells, and NiVpp transduced human embryonic, hematopoietic, and neural stem cell populations in an ephrinB2-specific manner. Intravenous administration of luciferase reporter-expressing NiVpp resulted in signals detected in the spleen and lung but not in the liver. Biodistribution studies quantifying genome-integrated vector copy numbers in various tissues confirmed these observations. Bypassing the liver sink is a critical barrier for targeted gene therapy $(23,24)$, suggesting that the extraordinary specificity of $\mathrm{NiV}-\mathrm{G}$ for ephrinB2 may allow for targeting of specific ephrinB2 ${ }^{+}$ populations in vivo or in vitro, without the need for prior cell purification.

\section{MATERIALS AND METHODS}

Plasmid construction. The codon-optimized NiV-F and NiV-G genes were tagged at the C-terminal coding region with AU1 (DTYRYI) and hemagglutinin (YPYDVPDYA) tags, respectively, as previously described (25). The $\beta$-lactamase ( $\beta$ la) gene was fused to the NiV-M gene as previously described (26). NiV-G cytoplasmic truncation mutants were generated using a QuikChange site-directed mutagenesis kit (Stratagene, Cedar Creek, TX) with primers designed to correspond to the deletions. NiV T5F and T5F $\Delta \mathrm{N} 3$ mutants were made previously $(27,28)$. FUhLucW and FG12 were constructed from FUGW as previously described $(29,30)$. pNL4-3.Luc. $\mathrm{R}^{-}$. $\mathrm{E}^{-}$was obtained through the NIH AIDS Research and Reference Reagent Program. VSV- $\Delta$ G-Luc has the G protein envelope replaced with Renilla Luc, as previously described (19).

Cells and culture conditions. 293T cells were cultured in Iscove's modified Dulbecco's medium (IMDM) with $10 \%$ fetal bovine serum (FBS), 1\% minimal essential medium (MEM) nonessential amino acids (NEAA), 1\% Glutamax, and antibiotics. CHO-pgsA745 is a mutant cell line derived from Chinese hamster ovary $(\mathrm{CHO})$ cells that lack the endogenous expression of heparin sulfate proteoglycans (31) and was maintained in Dulbecco's modified Eagle's medium (DMEM)-F-12 medium supplemented with $10 \%$ FBS. CHO cells expressing either ephrinB2 (CHO-B2) or ephrinB3 (CHO-B3) were made as previously described (19) and maintained in DMEM-F-12 medium supplemented with $10 \%$ FBS and $1 \mathrm{mg} / \mathrm{ml}$ of G418 to drive plasmid expression through neomycin resistance. Vero (African green monkey kidney fibroblast) cells were maintained in alpha minimal essential medium ( $\alpha$-MEM) with 10\% FBS. U87 cells were maintained in DMEM with 10\% FBS. Human embryonic stem cells (hESCs) (H1, H9, and UCLA1 lines) were cultured on gelatincoated plates on a feeder layer of mitotically inactivated murine embryonic fibroblasts (MEFs). hESC medium was composed of DMEM-F-12 supplemented with $20 \%$ KnockOut serum replacement (KOSR; Life Technologies), $0.1 \mathrm{mM}$ NEAA (Life Technologies), $1 \mathrm{mM}$ L-glutamine (Life Technologies), $0.1 \mathrm{mM}$ 2-mercaptoethanol (Sigma-Aldrich), and 4 $\mathrm{ng} / \mathrm{ml}$ basic fibroblast growth factor (bFGF; R\&D Systems [obtained via the National Cancer Institute Biological Resources Branch]). hESCs were passaged in small clumps every 5 to 7 days by use of collagenase (Life Technologies). For viral transductions, hESCs were transferred to feederfree conditions. hESCs were dissociated to single cells for counting by use of trypsin (Life Technologies) and then plated on Matrigel (BD Biosciences)-coated plates in hESC medium that was conditioned overnight on MEFs and supplemented with $10 \mu \mathrm{M}$ HA-1077 (ROCK inhibitor; SigmaAldrich) to promote hESC survival (32). CD34 ${ }^{+}$cells were isolated from human fetal liver as previously described (33). For viral transductions, the cells were seeded onto Retronectin (TaKaRa)-coated plates with $2 \%$ bovine serum albumin in Yssel's medium (Gemini). As previously described (34), neuralization of undifferentiated HSF1 hESC colonies was induced in situ by switching to rosette medium containing DMEM-F-12, N-2 supplement (Gibco), B27 supplement (Gibco), $1 \mu \mathrm{M}$ retinoic acid (Sigma), $1 \mu \mathrm{M}$ Smoothened agonist (Calbiochem), and $20 \mathrm{ng} / \mathrm{ml} \mathrm{FGF2.}$ After 10 to 14 days, rosettes were mechanically isolated and passaged onto polyornithine (Sigma)- and laminin (Sigma)-coated plates. Once picked, rosettes were placed into neural progenitor cell (NPC) medium containing DMEM-F-12, N-2, B27, $50 \mathrm{ng} / \mathrm{ml}$ epidermal growth factor (EGF; Peprotech), and $20 \mathrm{ng} / \mathrm{ml} \mathrm{FGF}$, allowing for expansion and maintenance. A total of 100,000 NPCs (passage 2) were plated onto 24-well plates by use of TrypLE (Gibco) for viral infection.

Virus production. Lentiviral vectors were produced by calcium phosphate-mediated transient transfection of 293T cells. Twenty-four hours prior to transfection, $1.6 \times 10^{7} 293 \mathrm{~T}$ cells were seeded into a T175 flask. On the day of transfection, the medium was replaced with $25 \mathrm{ml}$ fresh medium containing $10 \mathrm{mM}$ chloroquine. Seven micrograms of NiV-F variant, $7 \mu \mathrm{g}$ of NiV-G variant, $12.5 \mu \mathrm{g}$ of the packaging plasmid 
pCMV $\Delta$ R8.9, and $12.5 \mu \mathrm{g}$ of the lentiviral transfer vector plasmid (FG12 or FUhLucW) were mixed with $133 \mu \mathrm{l}$ of $2 \mathrm{M} \mathrm{CaCl}_{2}$ and brought up to a final volume of $980 \mu \mathrm{l}$ with double-distilled water $\left(\mathrm{ddH}_{2} \mathrm{O}\right)$. Next, 1,110 $\mu l$ of $2 \times$ HEPES-saline buffer was added dropwise. Following a 20 -min incubation on ice, the precipitate was added to the cells. After $8 \mathrm{~h}$, the medium was replaced with $30 \mathrm{ml}$ of AIM-V serum-free medium. At $48 \mathrm{~h}$ posttransfection, the cell supernatant containing the pseudotyped lentiviral vector particles was layered over a $20 \%$ sucrose cushion and concentrated by centrifugation at $28,000 \mathrm{rpm}$ at $4^{\circ} \mathrm{C}$ for $2 \mathrm{~h}$ (Beckman SW-32 rotor). The viral pellet was resuspended in $300 \mu$ l of phosphate-buffered saline (PBS) and filtered $(0.45-\mu \mathrm{m}$ filter). To determine viral titers, serial dilutions of unconcentrated and concentrated stocks were added to $2 \times$ $10^{5} 293 \mathrm{~T}$ cells and incubated for $2 \mathrm{~h}$ at $37^{\circ} \mathrm{C}$. The medium was replaced with fresh medium. At $72 \mathrm{~h}$ postinfection, the cells were collected and analyzed by flow cytometry for enhanced green fluorescent protein (EGFP) expression. The titers are expressed in infectious units per $\mathrm{ml}$ (IU/ml). A typical unconcentrated titer for NiVpp was $10^{6} \mathrm{IU} / \mathrm{ml}$, and they could be concentrated to $10^{8}$ to $10^{9} \mathrm{IU} / \mathrm{ml}$ upon ultracentrifugation.

Western blot analysis. Concentrated viral stocks were normalized to HIV p24 (50 ng of p24 per lane). The samples were boiled in $6 \times$ sodium dodecyl sulfate (SDS) loading buffer containing 2-mercaptoethanol for 10 min, subjected to electrophoresis through a $10 \%$ SDS-polyacrylamide gel, and transferred to a polyvinylidene difluoride (PVDF; Millipore) membrane. Mouse anti-hemagglutinin-tag (Covance), mouse anti-AU1-tag (Covance), and mouse anti-p24 (NIH AIDS Research and Reference Reagent Program) monoclonal antibodies were used to detect NiV-G, $\mathrm{NiV}-\mathrm{F}$, and p24 proteins, respectively. Goat anti-mouse-IRDye 800CW (Li-Cor Biosciences) was used as a secondary antibody. Signals were detected using an Odyssey infrared imaging system (Li-Cor Biosciences).

及la-M entry assay. NiV and VSV-G $\beta$-lactamase-matrix virus-like particles (ßla-M VLPs) were produced as previously described (26). $293 \mathrm{~T}$ cells were seeded in a 24 -well dish at $7.5 \times 10^{4}$ cells per well. Twenty-four hours after seeding, concentrated NiV wt F/wt G-, NiV T5F/wt G-, or VSV-G-pseudotyped Bla-M VLPs were added to the cells and spin inoculated for $1 \mathrm{~h}$ at $2,000 \mathrm{rpm}$ at $4^{\circ} \mathrm{C}$. After spin inoculation, cells were gently washed and CCF2-AM (Invitrogen) was added according to the manufacturer's recommendations. Cells were then transferred to a prewarmed $37^{\circ} \mathrm{C}$ microplate fluorometer (Tecan Infinite M1000). Green (uncleaved CCF2-AM) and blue (cleaved CCF2-AM) fluorescence was monitored at $530 \mathrm{~nm}$ and $460 \mathrm{~nm}$, respectively. Kinetic readings were taken every 10 min for up to $5 \mathrm{~h}$.

In vitro infection of cells. Increasing amounts of virus (based on the multiplicity of infection [MOI] or p24 normalization) were added to $1 \times$ $10^{5}$ cells of each cell type and centrifuged at $2,000 \mathrm{rpm}$ at $37^{\circ} \mathrm{C}$ for $2 \mathrm{~h}$. As a specificity control, $10 \mathrm{nM}$ soluble ephrinB2 (R\&D Systems) was added to the infection medium. To exclude pseudotransduction, $5 \mu \mathrm{M}$ nevirapine (NVP) was added. For stem cell transductions, $4 \mathrm{ng} / \mathrm{ml}$ of Polybrene (Sigma) was added. Following an overnight incubation with virus, the infection medium was removed and replaced with fresh medium. At $72 \mathrm{~h}$ postinfection, the cells were harvested and analyzed by flow cytometry for EGFP expression. For transduction of a mixed population of cells, ephrinB2 ${ }^{+}$human U87 cells were mixed with ephrinB2 ${ }^{-}$nonhuman $\mathrm{CHO}$ cells at different ratios (U87/CHO cell ratios of 1:1, 1:10, 1:100, and $1: 1,000)$ and seeded at a density of 50,000 cells per well in 24-well plates. The next day, cells were infected with 1 or $10 \mathrm{ng}$ of NiV T5F/wt G-, T5F $\Delta$ N3/wt G-, and VSV-G-pseudotyped particles. At $72 \mathrm{~h}$ postinfection, the cells were harvested and stained with the mouse W6/32 anti-human HLA-ABC monoclonal antibody (eBioscience) followed by Alexa 647conjugated goat anti-mouse secondary antibodies. Samples were fixed and then analyzed by dual-color flow cytometry for human HLA and EGFP expression.

Fluorescence-activated cell sorter (FACS) analysis of $\mathrm{CD}^{+} 4^{+}$fetal liver cells. $\mathrm{CD} 34^{+}$cells were isolated from human fetal liver as previously described (33). The cell suspensions were stained with DAPI $\left(4^{\prime}, 6\right.$-diamidino-2-phenylindole), CD34-allophycocyanin (APC), CD38-phyco- erythrin (PE)-Cy7, and CD90-fluorescein isothiocyanate (FITC) (BDBiosciences) antibodies for $20 \mathrm{~min}$ on ice in the dark. Following washing, the cells were sorted into the following 4 populations on a BD FACS Aria instrument: $\mathrm{CD} 90^{+} \mathrm{CD} 34^{+} \mathrm{CD} 38^{-}, \mathrm{CD} 90^{-} \mathrm{CD} 34^{+} \mathrm{CD} 38^{-}, \mathrm{CD} 90^{-}$ $\mathrm{CD} 34^{+} \mathrm{CD} 38^{+}$, and $\mathrm{CD} 90^{-} \mathrm{CD} 34^{-} \mathrm{CD} 38^{+}$cells. Immediately following sorting, RNA was extracted from each population by use of an RNeasy microkit (Qiagen) and used for preparation of cDNA by use of a QuantiTect reverse transcription kit (Qiagen). Specific primers for ephrinB2 (forward, TCCCGATTGAGCCTTACGACACTT; and reverse, TTCACC TTGACACAGAGCACC) and glyceraldehyde-3-phosphate dehydrogenase (GAPDH) (forward, ATCAAGAAGGTGGTGAAGCAGG; and reverse, TCAAAGGTGGAGGAGTGGGTGT) were used for real-time PCR analysis of gene expression.

Immunostaining. Coverslips were fixed in $4 \%$ paraformaldehyde (PFA) at room temperature for $15 \mathrm{~min}$, permeabilized in $0.5 \%$ Triton $\mathrm{X}-100$ at room temperature for $10 \mathrm{~min}$, and blocked in $5 \%$ bovine serum, $1 \%$ bovine serum albumin (BSA), and $0.2 \%$ Triton X-100 at room temperature for $30 \mathrm{~min}$. They were then incubated overnight at $4^{\circ} \mathrm{C}$ with a mouse anti-nestin antibody (Neuromics). Next, the coverslips were incubated with goat anti-mouse 594 (Molecular Probes) at room temperature for $1 \mathrm{~h}$ and then mounted in Prolong Gold with DAPI (Invitrogen). Imaging was performed using a Zeiss Axio Imager A1 microscope.

In vivo analysis of infection. Five-week-old female C57/BL6 mice (The Jackson Laboratory) were maintained in the animal facilities at UCLA in accordance with the University of California Animal Research Committee guidelines. The FUhLucW vector was pseudotyped with the VSV-G, T5F/wt G, or T5F $\Delta \mathrm{N} 3 / \mathrm{wt} \mathrm{G}$ envelope. Five or $10 \mu \mathrm{g}$ of p24 equivalents of each virus stock was injected into the tail vein. At 5 days postinjection, the mice were anesthetized and injected intraperitoneally with $3 \mathrm{mg}$ of D-luciferin (Xenogen). A cooled Ivis charge-coupled device (CCD) camera (Xenogen) was used to obtain whole-body images. Organs (brain, lung, heart, spleen, and liver) were excised from sacrificed mice for imaging. For biodistribution studies, which required the quantitation of integrated vector copy numbers in various tissues, the FG12 vector was pseudotyped with the VSV-G or NiV envelope. Five micrograms of p24 equivalents of each virus stock was administered as described above. At 4 days postinjection, the mice were sacrificed and organs (liver, spleen, lung, brain, heart, kidney, and bone marrow) were harvested. Organs were minced and cells dissociated as previously described (35). We modified the protocol to extend the digestion time to $1 \mathrm{~h}$. Genomic DNA was harvested using an Allprep kit (Qiagen). Quantitation of the vector copy number and cell number in the DNA isolate was performed with LightCycler 480 SYBR green I master mix (Roche) and a LightCycler 480 realtime PCR system (Roche). The FG12 plasmid was used as the standard for quantitation of vector copy numbers. The primers for the analysis of vector copy numbers were GFP-For (5'-GCAGAAGAACGGCATCAAGGT G-3') and GFP-Rev (5' -TGGGTGCTCAGGTAGTGGT-3'). The primers for the analysis of cell number were HPRT-For $\left(5^{\prime}\right.$-GCAGCGTTTCTGA GCCATT-3') and HPRT-Rev (5'-AAAGCGGTCTGAGGAGGA-3').

Gene expression analysis. The gene expression profiles of various pluripotent stem cell (PSC)-derived and primary (fetal and adult) tissues were determined by use of a human U133plus2.0 array (Affymetrix) at the UCLA Clinical Microarray Core. Multiple independent arrays $(>3)$ were performed for each cell type shown in Table 1.

\section{RESULTS}

Efficient pseudotyping of a lentiviral vector with the Nipah virus envelope glycoproteins requires truncations only in the cytoplasmic tail of the $\mathrm{F}$ protein. Previous studies have shown that pseudotyping of lentiviral vectors with unmodified paramyxoviral glycoproteins is highly inefficient (37). However, recent studies with the measles virus envelope showed that when the cytoplasmic tails of both the fusion $(\mathrm{F})$ and attachment $(\mathrm{H})$ glycoproteins were truncated, infectious particles were produced $(6,7)$. The highest titers were obtained when only 3 residues were left in the F protein 
TABLE 1 Tissue and cell type expression of ephrinB2and ephrinB3 ${ }^{a}$

\begin{tabular}{|c|c|c|c|c|c|c|c|c|c|c|c|c|}
\hline Gene & $\begin{array}{l}\text { Specificity } \\
\text { Marker }\end{array}$ & $\begin{array}{r}\text { Source: } \\
\text { Cell Type: }\end{array}$ & PSC & $\begin{array}{l}\text { PSC } \\
\text { DE }\end{array}$ & $\begin{array}{l}\text { Adult Tissue } \\
\text { Hepatocytes }\end{array}$ & $\begin{array}{c}\text { PSC } \\
\text { Neural } \\
\text { Progenitor }\end{array}$ & $\begin{array}{c}\text { PSC } \\
\text { Neurons }\end{array}$ & $\begin{array}{c}\text { Fetal Tissue } \\
\text { Neural } \\
\text { Progenitor }\end{array}$ & $\begin{array}{l}\text { Adult Tissue } \\
\text { Keratinocyte }\end{array}$ & $\begin{array}{l}\text { Adult Tissue } \\
\text { Mesothelial }\end{array}$ & \begin{tabular}{|c|} 
Adult Tissue \\
Kidney \\
Epithelial
\end{tabular} & $\begin{array}{c}\text { Adult Tissue } \\
\text { Blood } \\
\text { Vessels }\end{array}$ \\
\hline EFNB2 & & & 1186 & 716 & 85 & 2131 & 1794 & 3961 & 2244 & 1935 & 3008 & 5415 \\
\hline EFNB3 & & & 349 & 525 & 53 & 1622 & 7789 & 2275 & 273 & 190 & 219 & 184 \\
\hline GAPDH & Housekeeping & & 19143 & 17814 & 13047 & 17359 & 17637 & 17303 & 19032 & 22349 & 21258 & 19544 \\
\hline АСТВ & Genes & & 18106 & 18917 & 17098 & 18191 & 17065 & 19266 & 17449 & 20505 & 19893 & 18052 \\
\hline FABP7 & NPCs & & 281 & 64 & 22 & 4351 & 4640 & 15172 & 31 & 17 & 30 & 25 \\
\hline ALB & hepatocytes & & 13 & 11 & 22065 & 11 & 10 & 10 & 10 & 9 & 8 & 10 \\
\hline VWF & endothelium & & 65 & 105 & 67 & 63 & 49 & 40 & 37 & 46 & 31 & 12953 \\
\hline KRT14 & keratinocyte & & 13 & 11 & 13 & 12 & 12 & 11 & 19635 & 16 & 11 & 12 \\
\hline POU5F1 & PSCs & & 8332 & 13192 & 229 & 508 & 135 & 123 & 188 & 144 & 369 & 146 \\
\hline & & & Pluripotent & Endoderm & Endoderm & Ectoderm & Ectoderm & Ectoderm & Ectoderm & Mesoderm & Mesoderm & Mesoderm \\
\hline
\end{tabular}

${ }^{a}$ A human U133plus2.0 array (Affymetrix) was used to examine various PSC-derived and primary (fetal and adult) tissues to examine whole-genome expression. Data shown here are normalized mean expression values for multiple biological repeats ( $\geq 3$ ). The ephrinB2 and -B3 genes (yellow for significant positive results), housekeeping genes (gray), and cell-specific genes (red) are color coded as indicated. PSC, pluripotent stem cell; DE, definitive endoderm derived from PSCs cultured in chemically defined medium (CDMABFLY) supplemented with Activin, BMP4, FGF2, and the phosphatidylinositol 3-kinase (PI3K) inhibitor LY294002. DE gives rise to other endoderm progenitors (pancreatic, endocrine, etc.) and can retain expression of the POU5F1 pluripotency marker (also called Oct4) during early stages of PSC-to-DE differentiation (36).

cytoplasmic tail and 15 residues were left in the H protein cytoplasmic tail. In contrast, a study with the NiV envelope showed that the full-length glycoproteins (F and G) could be used to pseudotype a lentiviral luciferase reporter vector, although a truncated F mutant with only 4 residues left in its cytoplasmic tail did result in a 10 -fold increase in luciferase expression compared to that with wild-type F (16). However, no data regarding the infectious titers produced were given, and neither the transduction efficiency of NiVpp on relevant primary cells nor the potential of NiVpp for targeted transduction in vivo was examined.

To confirm and extend these findings, we took advantage of a previously characterized truncated variant of NiV-F, T5F (27), with 5 residues left in the cytoplasmic tail (Fig. 1A, top panel) but otherwise expressed and processed at wild-type levels (27). When T5F was used in combination with wild-type (wt) NiV-G to pseudotype the FG12 lentiviral vector containing a GFP reporter gene, T5F/wt G NiVpp gave a titer of $\sim 10^{6} \mathrm{IU} / \mathrm{ml}$ on $293 \mathrm{~T}$ cells, a $100-$ fold increase in titer compared to that for wt F/wt G NiVpp (Fig. 1B). Pseudotyping of NiV T5F/wt G onto the pNL4-3-Luc- $\mathrm{E}^{-} \mathrm{R}^{+}$ vector that was used in the above-mentioned study (16) also resulted in a 100-fold increase in luciferase expression compared to that with wt F/wt G NiVpp across a 3-log dilution of the virus stock (Fig. 1C). However, pNL4-3-Luc- $\mathrm{E}^{-} \mathrm{R}^{+}$is obviously not suitable as a gene therapy vector, as it expresses the entire set of HIV genes except for the Env gene and lacks the cardinal safety features of lentivirus-based gene therapy vectors. Thus, in our subsequent studies, we focused on using the FG12 vector, an HIVderived self-inactivating lentiviral vector designed for gene therapy purposes $(30,33)$.

In an effort to further increase viral titers, we generated variants with stepwise truncations in the NiV-G cytoplasmic tail (Fig. 1A, bottom panel) and screened them in combination with T5F. Although the T5F/ $\Delta 10 \mathrm{G}$ and $\mathrm{T} 5 \mathrm{~F} / \Delta 25 \mathrm{G}$ variants demonstrated titers similar to those with T5F/wt G, none of the NiV-G variants produced higher titers than those with wt G (Fig. 1B). Moreover, all combinations of wt $\mathrm{F}$ with the different NiV-G truncation variants produced extremely low titers (data not shown). Collectively, these results indicate that only truncations in NiV-F are critical for producing high-titer functional pseudotyped parti- cles in combination with wt NiV-G. Thus, all subsequent experiments were performed with the $\mathrm{T} 5 \mathrm{~F} / \mathrm{wt} \mathrm{G}$ variant as a starting point. Like the case for VSV-Gpp, NiVpp could be concentrated by ultracentrifugation without a loss of infectivity to produce titers of $\sim 10^{8}$ to $10^{9} \mathrm{IU} / \mathrm{ml}$, compared to $10^{10}$ $\mathrm{IU} / \mathrm{ml}$ for VSV-G (data not shown).

To determine whether the difference in titer between T5F/wt G and wt F/wt G NiVpp was due to the efficiency of envelope incorporation onto the lentiviral particle, we purified NiVpp by ultracentrifugation and determined the amounts of $F$ and $G$ on an equivalent amount of virions (normalized by the amount of HIV capsid p24) by Western blotting. Unlike the case for MeVpp, where full-length wt $\mathrm{F}$ and wt $\mathrm{H}$ were not detectably incorporated into pseudotyped particles, there was no difference in the levels of NiV-F and -G incorporated between wt F/wt G and T5F/wt G NiVpp (Fig. 1D). In addition, both wt $\mathrm{F}$ and T5F were equivalently processed $\left(\mathrm{F}_{0} / \mathrm{F}_{1}\right)$. Thus, truncation of the NiV-F cytoplasmic tail did not necessarily enhance incorporation onto virus particles, as demonstrated by studies with the measles virus envelope $(6,7,38)$. This suggests that there may be some incompatibility of the cytoplasmic tail of wild-type NiV-F with the matrix (Gag) protein of HIV that compromises the fusogenicity of NiV-F, and hence the infectivity of NiVpp.

We hypothesized that if the incompatibility is specific to the HIV Gag protein, then wt F/wt G "pseudotyped" onto the NiV matrix (NiV-M) to make infectious VLPs should not show a significant difference in infectivity compared to VLPs produced with T5F/wt G. To test this, we used an established $\beta$-lactamase-NiV matrix ( $\beta$ la-M)-based assay to compare entry of wild-type NiV-F and T5F VLPs (26). In this assay, entry of VLPs is detected by cytosolic delivery of $\beta$ la-M to target $293 \mathrm{~T}$ cells preloaded with the fluorescent CCF2-AM substrate. Bla-mediated cleavage of CCF2-AM results in a shift from green to blue fluorescence. Thus, the blue-to-green fluorescence ratio can be monitored in real time to compare the relative differences in entry efficiency due to viruscell fusion. Figure 1E shows that the rate and extent of virus-cell fusion between wt F and T5F VLPs were very similar, plateauing at ratios of 2.38 and 2.65, respectively. To further confirm this finding, we pseudotyped wild-type NiV-G with either NiV-F or T5F 
A

\begin{tabular}{|lllll|}
\hline NiV-F: & EKKRNT & YSRL EDR RVRPTSSGDLMMGT DTYRY \\
NiV.F TS: & EKKRNT & $\ldots$ & $\ldots$ & $\ldots \ldots \ldots \ldots \ldots \ldots$ DTYRY \\
\hline
\end{tabular}

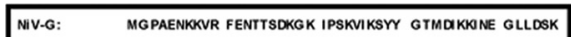

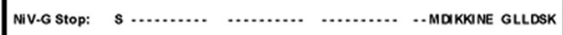
NiV.GA 5: MG..... KVR FENTTSDKGK IPSKMKSYY GTMOKKANE GLLDSK NiV.GS 10: MG ............ NTTSDKGK IPSKNKSTY GTMDIKRNE GLLDSK NIV-GA 15: MG ................ KGK IPSKVIKSYY GTMDIKRINE GLLDSK NIV-GA ZO: MG..................... . sKMIKSW GTMAKRNE GLLOSK Niv-GA 25: MG ............................sYY GTMDKKNE GLLDSK Niv-Ga 30: GTMOKKNE GLLOSK
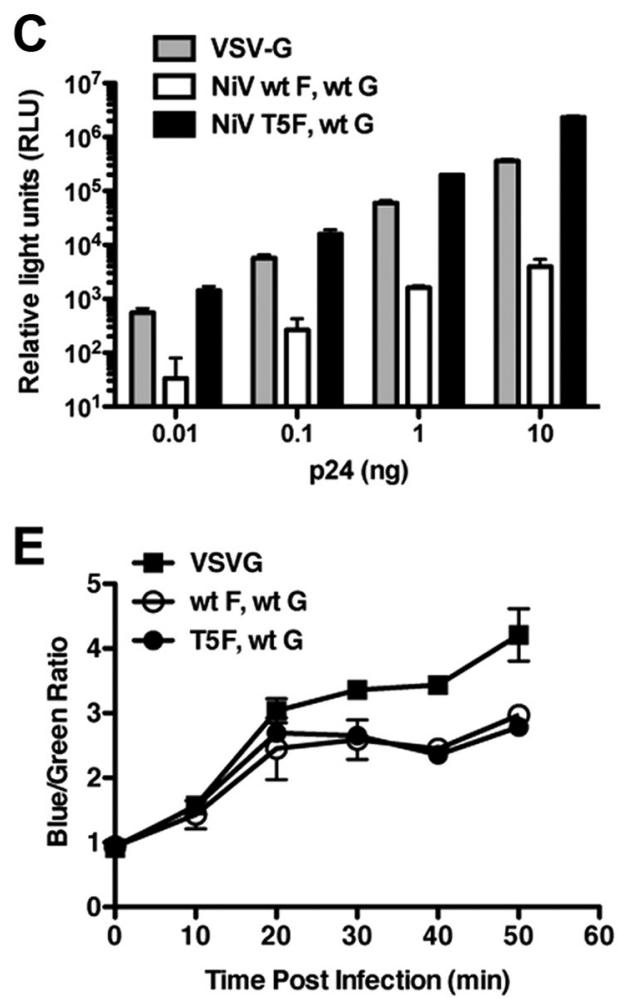

B

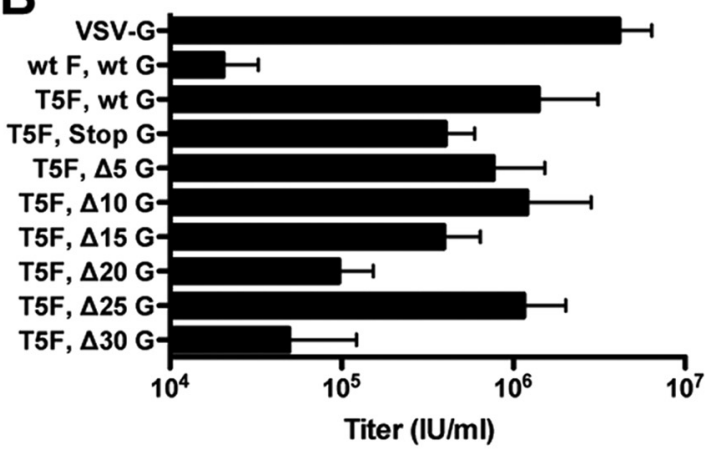

D

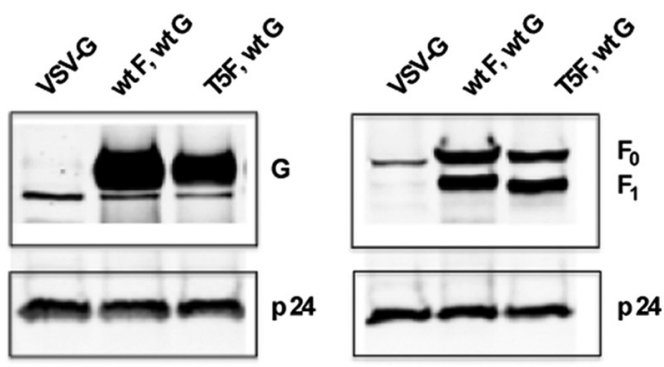

$\mathbf{F}$

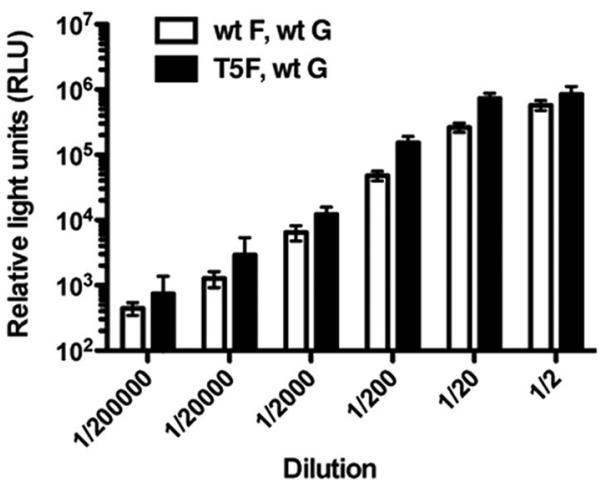

FIG 1 Characterization of NiV-F and -G protein variants used for pseudotyping of an HIV-1-derived lentiviral vector. (A) Amino acid sequences of the cytoplasmic tails of NiV-F (top) and -G (bottom) protein variants. T5F is a previously described cytoplasmic tail truncation of NiV-F (27). The 6 amino acids to the right are the AU1 tag at the cytoplasmic $\mathrm{C}$ terminus of the $\mathrm{F}$ protein. Stepwise truncations in the cytoplasmic tail of NiV-G were generated and screened in combination with T5F for the ability to form functional lentivirus pseudotypes. (B) Pseudotyped lentiviruses were made with the FG12 vector, in which the UbiC promoter drives EGFP expression. Codon-optimized NiV-F and NiV-G genes were transfected at a 1:1 ratio, and supernatants were harvested $48 \mathrm{~h}$ after transfection. Serial dilutions of unconcentrated viral supernatants were titrated on 293T cells. Cells were examined for GFP expression at $72 \mathrm{~h}$ postransduction by FACS analysis. Titers are expressed in IU/ml. Data shown are averages and standard deviations for three independent experiments. (C) pNL4-3.Luc. $\mathrm{R}^{-}$. $\mathrm{E}^{-}$was pseudotyped with the VSV-G or NiV envelope. 293T cells were infected with $0.01 \mathrm{ng}, 0.1 \mathrm{ng}, 1 \mathrm{ng}$, or $10 \mathrm{ng}$ (p24 equivalents) of VSV-Gpp or NiVpp. At $72 \mathrm{~h}$ postinfection, the cells were lysed and analyzed for luciferase activity. Data shown are averages and standard deviations for three replicates. (D) Western blot analysis of HIV-1-pseudotyped particles pseudotyped with VSV-G and NiV wild-type or variant proteins. NiV-F was detected using an anti-AU1 antibody, and NiV-G with an anti-hemagglutinin antibody. Representative blots from one of three experiments are shown. (E) VLPs were produced with NiV ßla-M and the VSV-G, NiV wt F/wt G, or NiV T5F/wt G envelope. Based on densitometry of $\beta$ la-M blots, equivalent amounts of concentrated VLPs were added to $293 \mathrm{~T}$ cells for $1 \mathrm{~h}$ at $4^{\circ} \mathrm{C}$ and then incubated with CCF2-AM substrate at $37^{\circ} \mathrm{C}$. The blue/green fluorescence ratios were monitored as a measure of virus-cell fusion as described in Materials and Methods. Data are presented as blue/green ratios at 10-min intervals. Kinetic readings up to the 50-min time point are shown. Duplicate readings were taken at each time point. Data shown are averages \pm standard deviations for three independent experiments. (F) A VSV- $\Delta$ G-Luc core was pseudotyped with the NiV wt F/wt G or NiV T5F/wt G envelope as previously described (19). Serial dilutions of unconcentrated viral supernatants were titrated on Vero cells. At $24 \mathrm{~h}$ postinfection, the infected cells were lysed and analyzed for luciferase activity. Data shown are averages and standard deviations for four replicates.

onto a VSVAG-rLuc core and infected 293T cells with 10-fold dilutions of each virus stock. T5F NiVpp demonstrated only up to a 2-fold difference in relative light units (RLU) compared to wt F NiVpp (Fig. 1F). Thus, the 100 -fold difference in titers of wt F and
T5F lentiviral pseudotypes was most likely due to a specific incompatibility of the long cytoplasmic tail of NiV-F with HIV Gag that compromises the fusogenic activity of NiV-F but not its ability to be incorporated into lentiviral particles. 


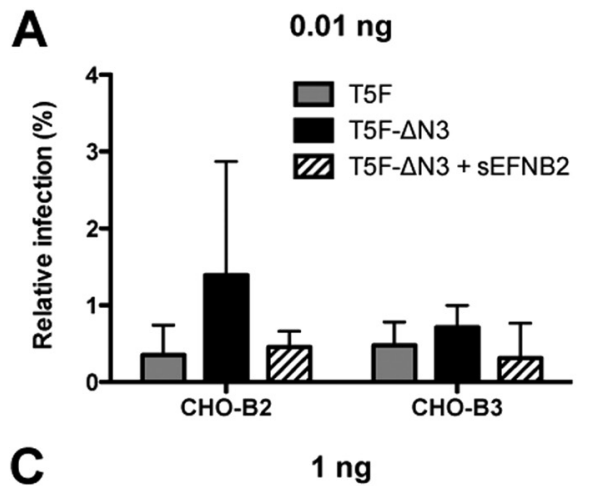

B $\quad 0.1 \mathrm{ng}$
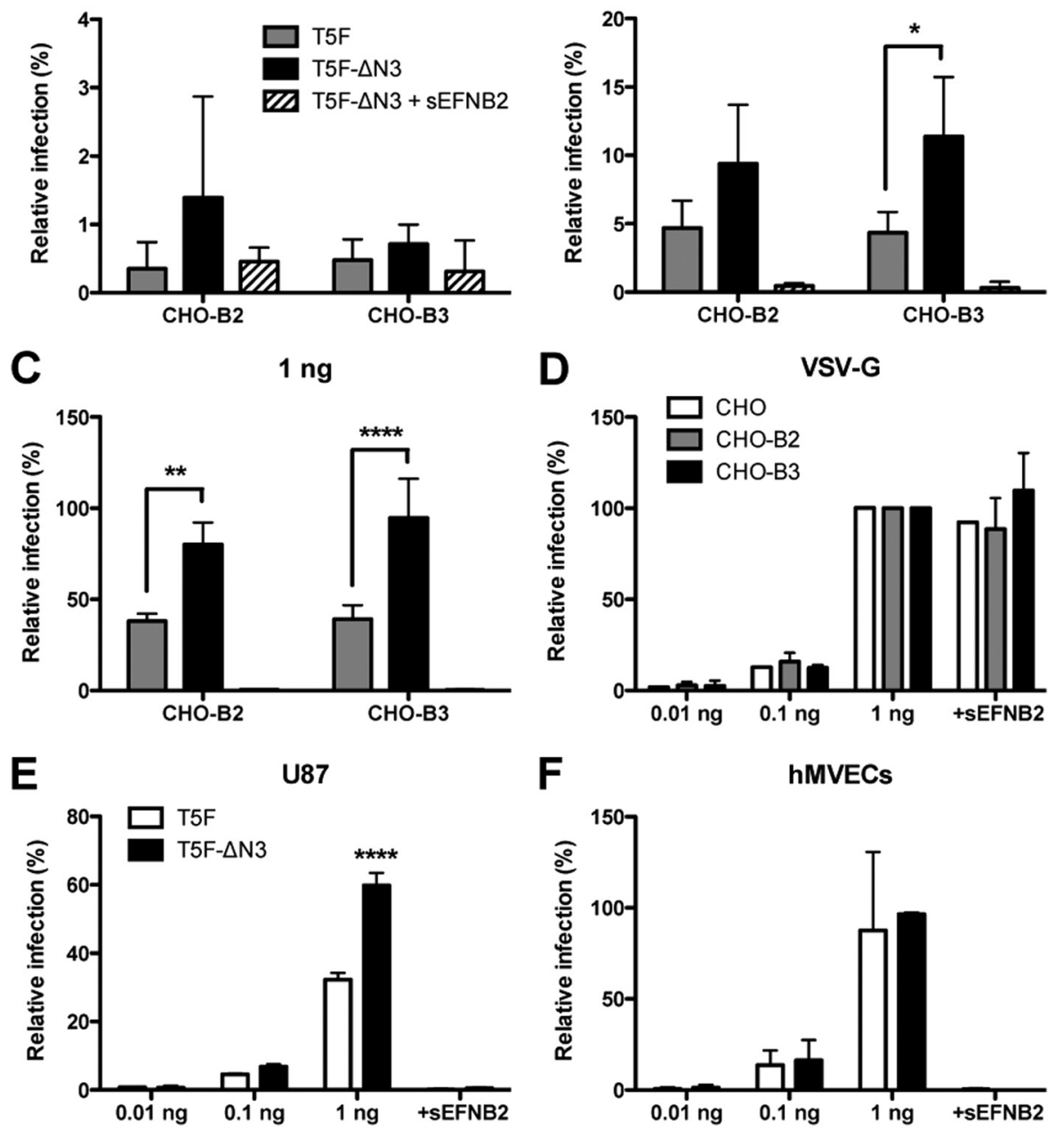

FIG 2 The NiV T5F $\Delta$ N3/wt G hyperfusogenic mutant demonstrates increased infectivity in vitro. (A to D) CHO, CHO-B2, and CHO-B3 cells were infected with $0.01 \mathrm{ng}, 0.1 \mathrm{ng}$, or $1 \mathrm{ng}$ (p24 equivalents) of NiV envelope (A to C) or VSV-G (D) lentiviral pseudotypes carrying the GFP reporter gene (CHO cell data are not

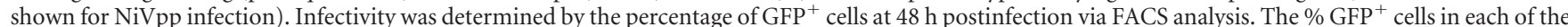
CHO cell lines infected by VSV-Gpp at maximal viral input (1 ng) was set at 100\%, and all other infections in that cell line were normalized to this value. For reference, at $1 \mathrm{ng}$, VSV-Gpp infected $20.2 \%$ of CHO cells, $22.7 \%$ of CHO-B2 cells, and 21.6\% of CHO-B3 cells. For clarity of comparisons, the relative infectivities of T5F/wt G NiVpp versus the hyperfusogenic T5F $\Delta \mathrm{N} 3 / \mathrm{wt} \mathrm{G}$ variant on CHO-B2 and CHO-B3 cells, using low $(0.01 \mathrm{ng})$, medium $(0.1 \mathrm{ng})$, and high (1 ng) viral inocula, are shown separately in panels A, B, and C, respectively. U87 cells (E) and HMVECs (F) were infected with T5F/wt G and T5F $\Delta$ N3/wt G NiVpp as described for panels A to C, but normalized to VSV-Gpp infection of the same cell line (U87 cells or HMVECs) at maximal viral input (1 ng). For reference, at $1 \mathrm{ng}$, VSV-Gpp infected $36.5 \%$ of U87 cells and 14.4\% of HMVECs. Inhibition by $10 \mathrm{nM}$ soluble ephrinB2 (sEFNB2) was used to demonstrate the specificity of NiV receptor-mediated entry. All pseudotyped particle infections, regardless of the envelope used, were also abrogated by $5 \mu \mathrm{M}$ NVP, a reverse transcriptase inhibitor (data not shown). Data shown in all panels are averages and standard deviations for three independent experiments. Statistical analyses were performed using a two-way analysis of variance (ANOVA) with Bonferroni posttest comparison, using GraphPad Prism. ${ }^{\star}, P<0.05$; $^{* *}, P<0.01$; $^{* * * *}, P<0.0001$.

A hypoglycosylated hyperfusogenic NiV-F mutant demonstrates increased infectivity in vitro. EphrinB2 is likely the primary entry receptor for $\mathrm{NiV}(17,18)$, while ephrinB3 may serve as an alternate receptor on some cell types $(19,39)$. CHO cells do not express endogenous ephrin 32 and - $\mathrm{B} 3$ and are therefore refractory to NiV envelope-mediated infection. However, stable $\mathrm{CHO}$ cell lines expressing ephrinB2 (CHO-B2) or ephrinB3 (CHO-B3) can readily support $\mathrm{NiV}$ infection (19). To compare the relative entry efficiencies of NiVpp via the ephrinB2 and ephrinB3 receptors, we first infected CHO-B2 and CHO-B3 cells with 0.01, 0.1, and $1 \mathrm{ng}$ p24 equivalents of NiVpp bearing T5F/wt G (Fig. 2A to C, gray bars) and then normalized the infectivity observed with that obtained with 1 ng of VSV-Gpp (Fig. 2D). Since VSV-Gpp infec- tion should not depend on the presence of ephrinB2 or -B3, this normalization allows for comparison across multiple independent experiments. Figure 2A to $\mathrm{C}$ shows that T5F/wt G NiVpp infected similar percentages of CHO-B2 and CHO-B3 cells in a dose-dependent manner, such that at the maximal viral input (1 ng p24), 38\% of CHO-B2 and 39\% of CHO-B3 cells were infected relative to the case with an equivalent amount of VSV-Gpp (compare Fig. $2 \mathrm{C}$ and $\mathrm{D}$, gray bars, at $1 \mathrm{ng}$ ).

Since we found that only modifications to NiV-F were critical for pseudotyping (Fig. 1), we sought to further improve the transduction efficiency by pseudotyping lentiviral particles with a hyperfusogenic NiV-F variant in which an N-linked glycosylation site has been removed (T5F $\Delta \mathrm{N} 3$ ) (28). The titer of T5F $\Delta \mathrm{N} 3 / \mathrm{wt} \mathrm{G}$ 
NiVpp on highly permissive 293T cells was similar to that of T5F/wt G NiVpp (data not shown). However, on CHO-B2 cells, the hyperfusogenic T5F $\Delta \mathrm{N} 3 /$ wt G NiVpp consistently exhibited a 2-fold increase in infectivity relative to the T5F/wt G NiVpp (Fig. $2 \mathrm{~A}$ to $\mathrm{C}$ ). This held true across a 100-fold difference in the amount of viral inoculum used. Although receptor specificity is determined by the attachment protein, there are examples of hyperfusogenic mutations in paramyxoviral $F$ proteins that enable fusion triggering in the absence of their homotypic attachment proteins (40-43). This does not appear to be true for the hyperfusogenic $\mathrm{NiV}-\mathrm{F}$ protein, as the increased infectivity of $\mathrm{T} 5 \mathrm{~F} \Delta \mathrm{N} 3 / \mathrm{wt} \mathrm{G}$ NiVpp was abrogated by soluble ephrinB2. Similar results were observed on CHO-B3 cells at moderate $(0.1 \mathrm{ng})$ and high (1 ng) viral input levels (Fig. 2B and C, compare black and gray bars); however, no specific infectivity was detected on $\mathrm{CHO}-\mathrm{B} 3$ cells at the lowest viral inoculum level (Fig. 2A). At the highest viral inoculum used, T5F $\Delta$ N3/wt G NiVpp infection approached the transduction efficiency of VSV-Gpp, infecting $80 \%$ and $97 \%$ of CHO-B2 and CHO-B3 cells, respectively (Fig. 2D).

Lastly, since ephrinB2 is expressed endogenously at high levels on endothelial cells and cells of the central nervous system (CNS), we compared the transduction efficiencies of T5F/wt G and T5F $\Delta$ N3/wt G NiVpp on human microvascular endothelial cells (HMVECs) and the U87 glioblastoma cell line (Fig. 2E and F). The 2-fold increase in infection efficiency of T5F $\Delta$ N3/wt G over T5F/wt G NiVpp was observed for U87 cells (59.8\% versus $32.3 \%$ at $1 \mathrm{ng}$ ) but not for HMVECs (96.6\% versus $87.6 \%$ ), which were already highly permissive to NiVpp infection. In summary, although both pseudotypes had similar infectivities on highly permissive cells such as $293 \mathrm{~T}$ cells and HMVECs, the hyperfusogenic T5F $\Delta$ N3/wt G NiVpp nevertheless exhibited increased infectivity on some cell lines.

NiVpp specifically target ephrinB2-positive cells in a vast excess of receptor-negative cells. Entry of T5F/wt $G$ and T5F $\Delta$ N3/wt G NiVpp into multiple cell types was inhibited by soluble ephrinB2 (Fig. 2), confirming the specificity of receptor-mediated entry. Next, we investigated whether the NiVpp could specifically target ephrinB2-positive cells in a mixture of ephrinB2-positive and -negative cells. U87 (ephrinB2-positive) cells were mixed with $\mathrm{CHO}$ (ephrinB2-negative) cells at ratios of 1:1, 1:10, 1:100, and 1:1,000 and were transduced with 1 or $10 \mathrm{ng}$ p24 equivalents of NiVpp or VSV-Gpp (Fig. 3). To distinguish infection of human U87 cells from infection of nonhuman $\mathrm{CHO}$ cells, the infected cells were stained with an anti-HLA (anti-major histocompatibility complex [MHC] class I) monoclonal antibody specific for human HLAs. At a 1:1 ratio of cells and $1 \mathrm{ng}$ of virus, the $\mathrm{GFP}^{+}$cells transduced by both the T5F/wt G and T5F $\Delta$ N3/wt G NiVpp remained entirely within the $\mathrm{HLA}^{+}$population (Fig. $3 \mathrm{~A}$, top panels). Increasing the amount of virus inoculum by 10 -fold $(10 \mathrm{ng})$ did not affect the specificity, since the NiVpp-transduced $\mathrm{GFP}^{+}$cells remained within the $\mathrm{HLA}^{+}$population (Fig. 3A, bottom panels). Furthermore, across all cell ratios, the NiVpp selectively transduced the ephrinB2 ${ }^{+}$U87 cells, even after accounting for the differential permissivity of CHO cells versus U87 cells for HIV-1-based lentiviral transduction (Fig. 3B and C). VSV-Gpp, on the other hand, transduced both $\mathrm{HLA}^{+}$and $\mathrm{HLA}^{-}$cells, indicating their relative lack of specificity. In sum, our data suggest that NiVpp can selectively target ephrinB2-positive U87 cells even in a 1,000-fold excess of ephrinB2-negative CHO cells (Fig. 3C). Our data also demonstrate that increasing the fusogenicity of NiVpp does not necessarily compromise the specificity.
NiVpp mediate entry into human embryonic, neural, and hematopoietic stem cells. On the basis of microarray and bioinformatic analyses, ephrinB2 has been identified as a molecular stem cell signature common to mouse ESCs, HSCs, and NSCs (22). To determine if ephrinB2 also marks their human stem cell counterparts, we determined if our NiVpp could mediate gene transfer into human ESCs, HSCs, and NSCs (Fig. 4). Indeed, adding increasing amounts of T5F/wt G NiVpp to H9 hESCs resulted in a dose-dependent increase (14 to $36 \%$ ) in the percentage of cells positive for GFP and SSEA-4, a cell surface human pluripotency marker (Fig. 4A). This infection was specific, as it was blocked by soluble ephrinB2 (Fig. 4B). To ensure that this ephrinB2-mediated transduction was not specific to the $\mathrm{H} 9 \mathrm{hESCline}$, we infected two other hESC lines (H1 and UCLA1) and obtained similar results (Fig. 4B). Since stem cells are more difficult to transduce than standard cell lines, we expected that the hyperfusogenic T5F $\Delta \mathrm{N} 3 / \mathrm{wt} \mathrm{G}$ variant would mediate entry more efficiently than $\mathrm{T} 5 \mathrm{~F} /$ wt G NiVpp. However, we did not see an increase in infection using T5F $\Delta$ N3/wt G NiVpp (Fig. 4C).

Next, we infected purified $\mathrm{CD} 34^{+}$cells isolated from human fetal liver with NiVpp. CD34 is expressed on human hematopoietic stem and progenitor cells (HSPCs), although only a small fraction of $\mathrm{CD}_{3} 4^{+}$cells are true HSCs that have extensive selfrenewal capacity in vitro and can engraft immunodeficient mice $(30,44)$. At an MOI of 1,000 , both T5F/wt G and T5F $\Delta$ N3/wt G NiVpp reproducibly transduced $3.6 \%$ and $3.5 \%$ of $\mathrm{CD}_{3} 4^{+}$cells, respectively. The specificity of this low-level infection was confirmed by blocking with soluble ephrinB2 (Fig. 4D). True human HSCs have two cardinal properties: multipotency, defined as the ability to differentiate into all blood cell lineages; and long-term (LT) self-renewal, defined by the inexhaustible ability to produce progeny functionally identical to the parent upon cell division (44). Human HSCs with these properties are enriched in the $\mathrm{Lin}^{-}$ $\mathrm{CD}^{+}{ }^{+} \mathrm{CD}_{3} 4^{+} \mathrm{CD} 38^{-}$fraction of cord blood (45). To determine whether ephrinB2 is expressed in this fraction, we sorted the following 4 populations from $\mathrm{CD} 34^{+}$cells isolated from human fetal liver: $\mathrm{CD}_{90}^{+} \mathrm{CD}^{+} 4^{+} \mathrm{CD} 38^{-}, \mathrm{CD}^{-} 0^{-} \mathrm{CD} 34^{+} \mathrm{CD} 38^{-}, \mathrm{CD} 90^{-}$ $\mathrm{CD}^{+} 4^{+} \mathrm{CD} 38^{+}$, and CD90 ${ }^{-} \mathrm{CD} 34^{-} \mathrm{CD} 38^{+}$cells (Fig. 4E). RNA was extracted from each sorted population, and ephrinB2 expression was quantified using real-time PCR analysis. Our results indicate that ephrinB2 was expressed at the highest level in the $\mathrm{CD}^{+}{ }^{+} \mathrm{CD} 34^{+} \mathrm{CD}^{-} 8^{-}$fraction (Fig. 4F). Thus, NiVpp may target the cognate population of $\mathrm{CD}_{3} 4^{+}$cells enriched for true HSC activity.

Lastly, we assessed the transduction efficiencies of NiVpp on nestin ${ }^{+}$NSCs derived from hESCs (Fig. 4G). Unlike the case with hESCs and CD $34^{+}$HSPCs, increasing the MOI resulted in a dosedependent increase in the percentage of NSCs transduced, such that the percentage of $\mathrm{GFP}^{+}$cells approached $100 \%$ at an MOI of 100 (Fig. 4H). However, similar to the hESC and hHSC transductions, the T5F $\Delta \mathrm{N} 3 /$ wt G NiVpp did not demonstrate increased infectivity compared to the T5F/wt G NiVpp. Nevertheless, we confirmed that ephrinB2 is functionally expressed on human ESCs, HSCs, and NSCs, at least at levels that can mediate NiVpp infection.

NiVpp bypass the liver sink in vivo. EphrinB2 is expressed on endothelial cells, smooth muscle cells, and neurons $(46,47)$. In contrast, ephrinB3 is not expressed in the endothelium and demonstrates overlapping but also distinct expression patterns in the central nervous system (48). This is consistent with our own mi- 
A

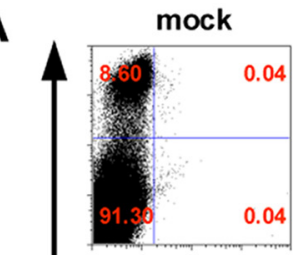

포

$$
\begin{array}{l|l}
\mathrm{A} & \mathrm{B} \\
\hline \mathrm{C} & \mathrm{D}
\end{array}
$$

T5F

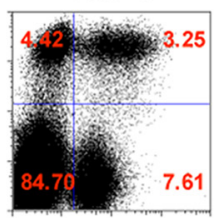

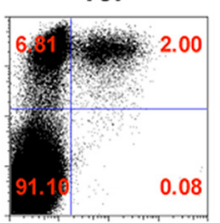

T5F- $\Delta \mathrm{N} 3$
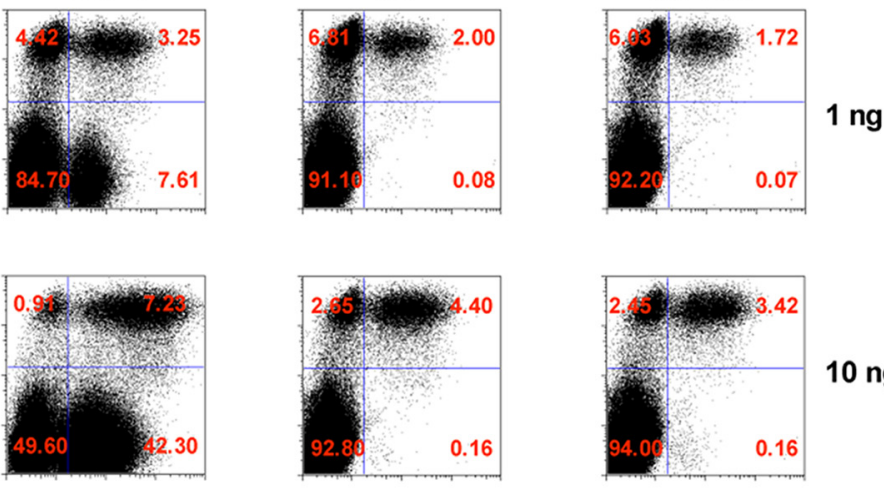

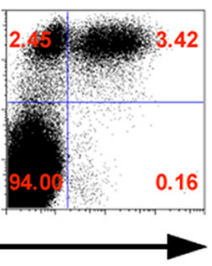

$10 \mathrm{ng}$

GFP

B

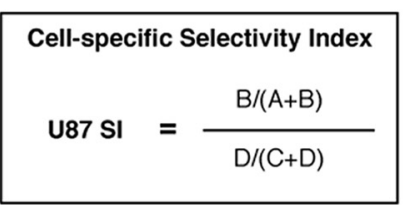

$\underline{\mathrm{U} 87: \mathrm{CHO}=1: 1}$

U87 SI

U87 SI

EphrinB2 SI

EphrinB2 SI

$\begin{array}{ll}1 \mathrm{ng} & 1.00 \\ 10 \mathrm{ng} & 1.00\end{array}$

NiV receptor-specific Selectivity Index

EphrinB2 SI $=\frac{(\text { VSV or NiV Env) U87 SI }}{\text { VSV-G U87 SI }}$

T5F

258.7

362.8

50.3

188.0
T5F- $\Delta$ N3

292.5

342.9

56.9

177.7
C

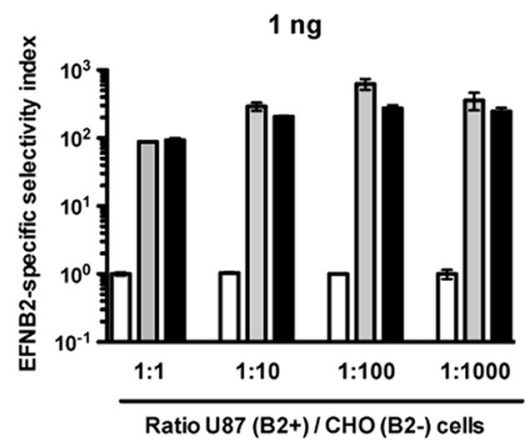

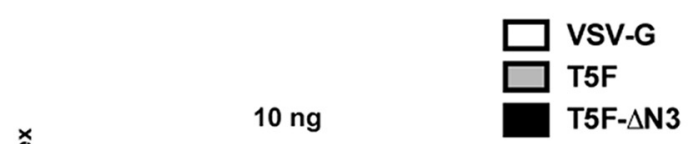

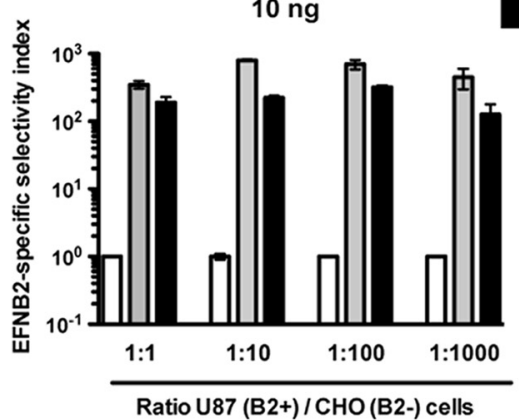

FIG 3 NiVpp can specifically target ephrinB2-positive cells in up to a 1,000-fold excess of ephrinB2-negative cells. (A) U87 (ephrinB2 ${ }^{+}$) cells were mixed with $\mathrm{CHO}\left(\right.$ ephrinB2 ${ }^{-}$) cells at different ratios (U87/CHO cell ratios of 1:1, 1:10, 1:100, and 1:1,000) and seeded at a density of 50,000 cells per well in 24-well plates. The next day, cells were infected with 1 or $10 \mathrm{ng}$ of NiV T5F/wt G-, T5F $\Delta \mathrm{N} 3 / \mathrm{wt}$ G-, or VSV-G-pseudotyped particles. At $72 \mathrm{~h}$ postinfection, the cells were harvested and stained with the W6/32 anti-human HLA-ABC monoclonal antibody, and the infection rate (\% GFP-positive cells) was determined by FACS analysis. Representative FACS plots are shown for data acquired from infection of a 1:1 mixture of U87 and CHO cells. Although the cells were seeded and infected at the indicated ratio, the $\mathrm{CHO}$ cells divided faster and outgrew the U87 cells by about 10-fold in each sample. Each FACS plot is representative of one of triplicate experiments at $1 \mathrm{ng}$ and one of duplicate experiments at $10 \mathrm{ng}$. Data from 300,000 cells were acquired for every condition used for analysis in panel B of this figure. (B) To take into account the differential permissivity of U87 and CHO cells to lentiviral transduction, we first calculated the "cell-specific selectivity index" for U87 cells (U87 SI) as follows: $\mathrm{SI}=[\mathrm{B} /(\mathrm{A}+\mathrm{B})] /[\mathrm{D} /(\mathrm{C}+\mathrm{D})]$, where $\mathrm{B}$ and $\mathrm{D}$ represent the \% infected $\left(\mathrm{GFP}^{+}\right) \mathrm{U} 87$ and $\mathrm{CHO}$ cells, respectively, and A and C represent their uninfected counterparts, such that the total fraction of $\mathrm{U} 87(\mathrm{~A}+\mathrm{B})$ and $\mathrm{CHO}(\mathrm{C}+\mathrm{D})$ cells in any given mixture upon analysis must equal $100 \%$. A U87 SI of $>1$ indicates a selective preference for infecting U87 over CHO cells. For VSV-Gpp, the U87 SI at 1 and 10 ng were 5.14 and 1.93, respectively. This likely reflects the receptor-independent preference for U87 over CHO cells due to the HIV-1-based vector backbone alone. The reduction in U87 SI at a higher inoculum of VSV-Gpp is also consistent with the known ability of VSV-G-delivered Gag to saturate nonhuman postentry restriction factors such as TRIM5 $\alpha$. Since VSV-G is not known to have a cell-type-specific receptor, we calculated the "NiV receptor-specific selectivity index" (ephrinB2 SI) as the VSV-G or NiV Env-specific U87 SI divided by the U87 SI for VSV-G. This normalized for differences in the intrinsic permissiveness of U87 over CHO cells for lentiviral transduction. This formulation now allows one to evaluate the selectivity of NiVpp for infecting ephrinB2-expressing cells relative to that of VSV-Gpp under all conditions analyzed. The values of the U87 SI and ephrinB2 SI for the data shown in panel A are indicated as an example of our analysis. (C) The ephrinB2 selectivity indexes for VSV-Gpp and NiVpp bearing T5F or T5F- $\Delta \mathrm{N} 3$ were calculated for all of the indicated conditions. Data shown are averages and standard deviations for triplicates done at $1 \mathrm{ng}$ and averages and ranges for duplicates done at $10 \mathrm{ng}$. 

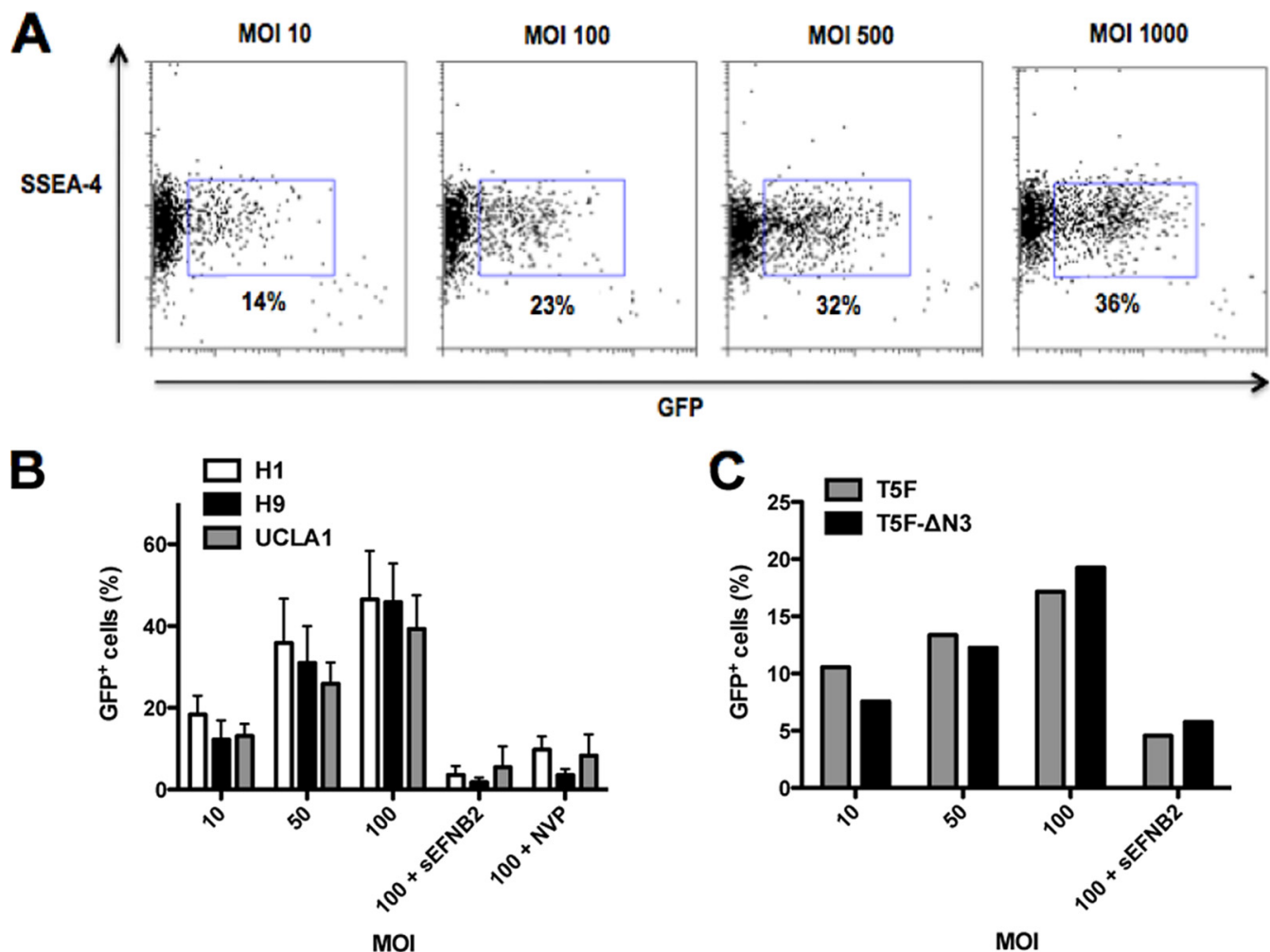

GFP

D

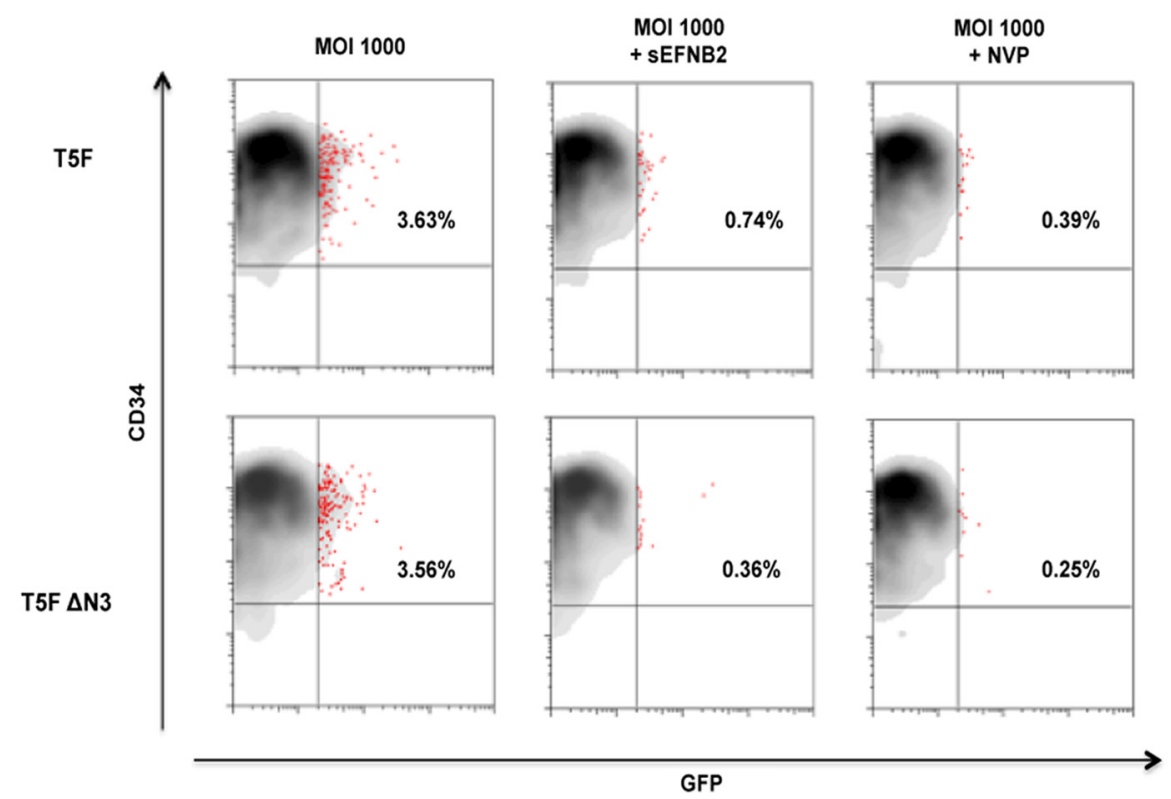

FIG 4 NiV-pseudotyped lentiviruses infect human embryonic, neural, and hematopoietic stem cells. (A) Increasing amounts of T5F/wt G NiVpp were added to H9 hESCs. Cells were stained for the cell surface pluripotency marker SSEA-4 and examined for GFP expression at $72 \mathrm{~h}$ postransduction by FACS analysis. (B) The $\mathrm{H} 1$ and UCLA1 hESC lines were infected with T5F/wt G NiVpp as in panel A. Infection was blocked with $10 \mathrm{nM}$ soluble ephrinB2 or $5 \mu \mathrm{M}$ nevirapine. Data shown are averages and standard deviations for three independent experiments. (C) H9 hESCs were infected with T5F/wt G and T5F $\Delta$ N3/wt G NiVpp as in panel A. Data from one of two experiments are shown. (D) Purified CD34 ${ }^{+}$cells from human fetal liver were infected with the indicated NiVpp in the presence or absence of $10 \mathrm{nM}$ sEFNB2 and $5 \mu \mathrm{M} \mathrm{NVP}$. At $72 \mathrm{~h}$ postransduction, cells were stained for the cell surface marker CD34 and analyzed for GFP expression by FACS analysis. Data for one representative donor of three is shown. (E) CD34 ${ }^{+}$cells isolated from human fetal liver were stained with CD90-FITC, CD34-APC, and CD38-PE-Cy7 antibodies and with DAPI and then sorted by FACS into 4 populations as indicated. Data shown are averages \pm standard deviations for 3 donors. (F) RNA was extracted from each cell population indicated in panel E, and ephrinB2 expression was examined by real-time PCR analysis and normalized against GAPDH as indicated in Materials and Methods. Data shown are averages and standard deviations for 3 donors. (G) Neural progenitors were derived from HSF1 hESCs and infected with NiVpp. At $72 \mathrm{~h}$ postransduction, cells were stained for nestin and examined by microscopy. (H) hNSC GFP expression at different MOIs $(0.01,0.05,0.1,0.5,1,5,10$, and 50$)$ was quantified by FACS analysis. Data shown in panels $\mathrm{G}$ and $\mathrm{H}$ are from one representative experiment out of four. 

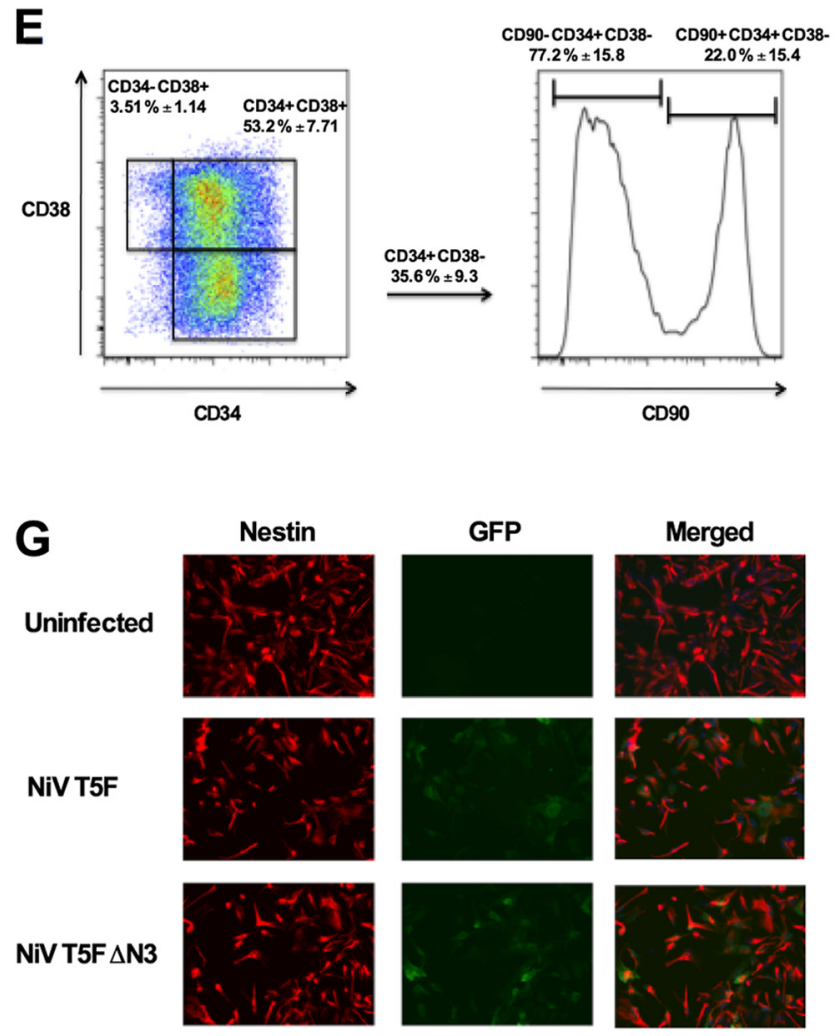

FIG 4 continued

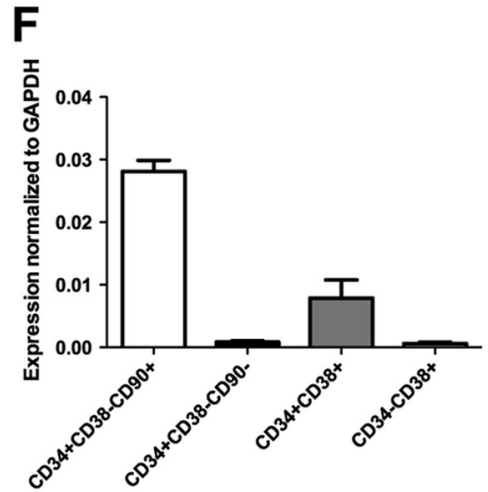

H

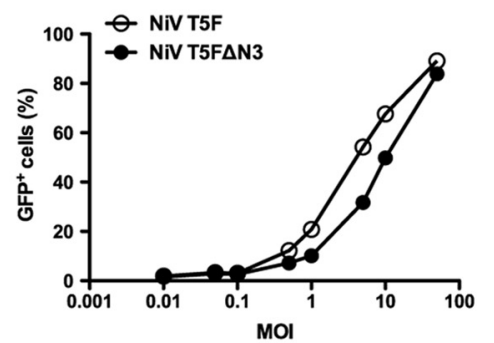

croarray expression studies of a variety of human and fetal tissuederived as well as PSC-derived cell types (Table 1). The ephrinB2 and ephrinB3 expression patterns are in concordance with NiV infection in vivo, since histopathological studies of human patients detected the highest levels of viral antigens in neurons and endothelial cells of small blood vessels in the brain, but some were also observed in the vasculature of the lung and spleen $(49,50)$. Importantly, no viral antigens were detected in the liver (50), also consistent with our data in Table 1, which show a lack of ephrinB2 and -B3 expression in adult tissue-derived hepatocytes.

The inability to detect viral antigens in liver autopsy tissues from $\mathrm{NiV}$-infected patients and the lack of viral receptor expression in the liver prompted us to examine whether intravenous administration of NiVpp might bypass the liver sink and target accessible ephrinB2 $2^{+}$cell types in vivo. We pseudotyped the FvcFlw lentiviral vector containing a firefly luciferase reporter gene with the NiV and VSV-G envelopes and administered the viruses intravenously through the tail vein of C57/BL6 mice (Fig. 5). A CCD camera was used to quantify the level of luciferase expression in the mice after injection of the D-luciferin substrate. Consistent with previous studies, VSV-Gpp-mediated transgene expression was detected primarily in the liver and spleen (Fig. 5B, top panels). For the T5F/wt G NiVpp, a slight signal was detected in the spleen in one case (Fig. 5B, middle panels). Strikingly, the T5F $\Delta$ N3/wt G NiVpp showed a substantially enhanced signal in the spleen in all cases and in the lung in one case (Fig. 5B, bottom panels). Thus, the T5F $\Delta \mathrm{N} 3 /$ wt G hyperfusogenic mutant demonstrates increased infectivity in vitro and in vivo. Significantly, neither the T5F/wt G nor T5F $\Delta \mathrm{N} 3 /$ wt G NiVpp exhibited any signal in the liver in all cases.
To complement and confirm these results, we also examined genomic vector integration in various tissues in an independent set of mice. The FG12 vector was pseudotyped with VSV-G and $\mathrm{NiV}$ envelopes, and viruses were administered as described above. At 4 days postinjection, whole organs (liver, spleen, and lung) were harvested and cells dissociated. Genomic DNA was extracted, and quantitation of vector integration was performed using real-time PCR analysis. This PCR-based assay was more sensitive (limit of sensitivity $=\sim 0.01$ vector integrant/10,000 cells) and confirmed key aspects of our luciferase imaging results: while VSV-Gpp and NiVpp transduced the spleen with high efficiencies, only VSV-Gpp transduced the liver, confirming that NiVpp clearly bypassed the liver sink (Fig. 5C). Interestingly, using the FG12 vector, VSV-Gpp also transduced the lung as well as NiVpp, although it is unclear whether the same cell types were transduced. The significance of these findings is discussed below.

\section{DISCUSSION}

Measles virus and Nipah virus belong to the only two paramyxovirus genera that use protein-based receptors for entry. Studies with the measles virus envelope have shown that complex modifications to its attachment protein, including disruption of the binding site for its natural receptors and appending $\mathrm{scFv}$ or other targeting domains, result in specific retargeting to desired cell populations in vitro and in vivo $(9,51)$. Some of these modifications have been adapted successfully to make scFv-directed-targeting lentiviral $\mathrm{MeVpp}(7,52)$. However, preexisting neutralizing antibodies due to widespread $\mathrm{MeV}$ vaccination may compromise the transduction efficiency of $\mathrm{MeVpp}$ administered in vivo, although deletion of immunodominant epitopes on $\mathrm{MeV}-\mathrm{H}$ and 


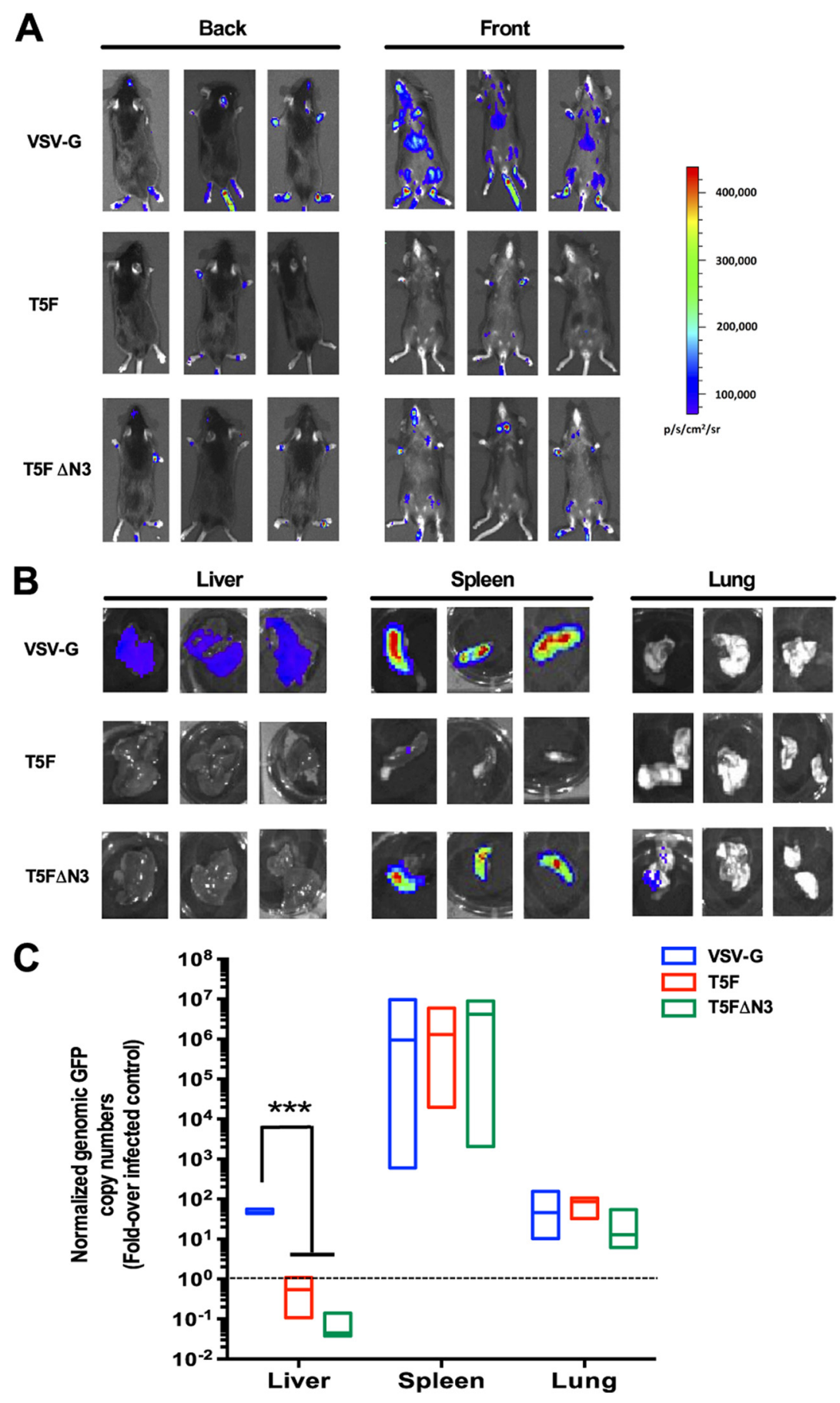

FIG 5 NiVpp bypass the liver sink in vivo. (A) The FvcFlw (firefly luciferase) vector was pseudotyped with VSV-G and the indicated NiV envelope. Five to $10 \mathrm{ng}$ of p24 equivalents of each pseudotyped lentivirus was injected into C57/BL6 mice through the tail vein. At 5 days postinjection, luciferase expression was monitored by CCD imaging of the whole animal after injection of the D-luciferin substrate as described in Materials and Methods. Three mice from three independent experiments are shown per virus. (B) Following whole-body imaging, each organ was isolated, and luciferase activity was imaged and quantified as described for panel A. Three organs from three different mice are shown per virus. (C) The FG12 (GFP) vector was pseudotyped with VSV-G and the indicated NiV envelope. Five micrograms of p24 equivalents of each pseudotyped lentivirus was administered to mice as described above. At 4 days postinjection, the mice were sacrificed and the indicated organs harvested. Genomic DNA was extracted, and the vector copy number was determined using real-time PCR analysis of GFP vector sequences. GFP copy numbers were normalized to hypoxanthine phosphoribosyltransferase (HPRT) copy numbers. Normalized GFP copy numbers are presented as fold increases over background numbers obtained from matched organs from an uninfected mouse. Three mice were used for each indicated pseudotyped vector (VSV-G, NiV-T5F, and NiV-T5F $\Delta 3$ ). The median and range are shown as box plots, using the average of quadruplicate values for each PCR. Statistical significance was assessed by $t$ tests corrected for multiple comparisons by the Holm-Sidak method in GraphPad Prism 6. ${ }^{* * *}, P<0.001$. 
other modifications have reduced the sensitivity of MeVpp to serum neutralization in vitro (53). In contrast, $\mathrm{NiV}$ is an emerging and lethal pathogen thus far confined to Southeast Asia (54). Thus, it is unlikely that preexisting antibodies will pose a barrier to the development of NiVpp as a vehicle for targeted gene therapy. However, in the case of $\mathrm{NiV}$, we sought to take advantage of the physiologically restricted and pathologically relevant expression patterns of ephrinB2, the primary high-affinity receptor for $\mathrm{NiV}$. Thus, instead of mimicking the retargeting strategies used for $\mathrm{MeV}$, we investigated the prospect of generating high-titer NiVpp that allow for specific targeting of biologically significant ephrinB2 ${ }^{+}$populations in vitro and in vivo.

The picomolar affinity of NiV-G for ephrinB2 is among the strongest viral envelope-receptor interactions known (12). This likely accounts for the extraordinary specificity of NiVpp for ephrinB2-expressing cells. We examined whether further increasing the efficiency of transduction on a per virion basis without compromising the specificity of NiV-G-mediated infection may facilitate the development of NiVpp for targeted gene therapy to ephrinB2-expressing cells. To that end, we generated NiVpp with hyperfusogenic $\mathrm{F}$ and wt $\mathrm{G}$ proteins. Our hyperfusogenic T5F $\Delta$ N3/wt G NiVpp appeared to infect some cell types (CHOB2, CHO-B3, and U87 cells) twice as well as T5F/wt G NiVpp did, but not other highly permissive cells, such as 293T cells and HMVECs, for which transduction efficiencies of the normo-fusogenic T5F/wt G NiVpp already approached that of VSV-Gpp.

Unexpectedly, in hard-to-transduce stem cell populations such as human ESCs and HSCs, the hyperfusogenic T5F $\Delta$ N3/wt G NiVpp also did not show an increase in transduction efficiency over that of T5F/wt G NiVpp. In addition, both demonstrated similar dose-dependent transduction efficiencies that plateaued at a relatively low percentage of the putative stem cell population. Thus, even at a saturating MOI of 1,000, both T5F- and T5F $\Delta$ N3based NiVpp transduced only $\sim 36 \%$ and $\sim 3.5 \%$ of SSEA- $4^{+}$ hESCs and CD $34^{+}$hHSCs, respectively. The limited transduction efficiencies seen with hESCs and CD34 ${ }^{+}$HSCs may be due to ephrinB2 expression on only a subset of these stem cell populations.

In hESCs, which are optimally passaged as colonies of cells, each colony contains heterogeneous subpopulations of cells that interact as an "ecosystem" to maintain the cardinal properties of hESCs: self-renewal and pluripotency $(55,56)$. For example, Stella- and Nanog-expressing subpopulations are biased toward self-renewal, whereas GATA-6-expressing subpopulations are more poised toward differentiation, and in between is a continuum of cells that contributes to the unique phenotypic properties of each hESC line (57). The ephrinB2 ${ }^{+}$subpopulation, or rather the fraction of ephrinB $2^{+}$cells that are maintained in hESC colonies, may be regulated to provide the optimal milieu for maintaining the cardinal properties of "stemness." This speculation is consistent with the known properties of ephrin-eph receptor-ligand interactions (both are receptor tyrosine kinases) for maintaining or enforcing tissue and cell type boundaries $(58,59)$. Thus, the ability to mark a subpopulation of hESCs with NiVpp-mediated transduction provides an experimentally tractable tool for examining the roles of these ephrinB2 ${ }^{+}$subsets in hESC fate, i.e., survival, self-renewal, and pluripotency.

On the other hand, only a small subpopulation of CD34 ${ }^{+}$cells are true multipotent HSCs capable of long-term (LT) self-renewal, operationally defined by multilineage reconstitution in im- munodeficient NOD-SCID mice. These LT-SCID repopulating cells can be found at least within the $\mathrm{CD} 34^{+} \mathrm{CD} 38^{-} \mathrm{CD} 90^{+}$subset $(45,60,61)$. Intriguingly, we found that ephrinB2 is expressed at the highest level in this subset (Fig. 4F). This is also consistent with the finding that ephrinB2 is found in the functional murine equivalent of LT-HSCs (22). Moreover, data from Fig. 4E and F indicate that the $\mathrm{CD}_{3} 8^{-} \mathrm{CD}^{+} 0^{+}$subset comprises less than $8 \%$ of total $\mathrm{CD}_{3} 4^{+}$cells from human fetal liver, which is close to but more than the $\sim 3.5 \%$ of CD $34^{+}$cells infected by NiVpp at the maximal MOI. Since LT-SCID repopulating cells are highly enriched in but do not comprise the totality of $\mathrm{CD} 34^{+} \mathrm{CD} 38^{-} \mathrm{CD} 90^{+}$cells, this raises the possibility that $\mathrm{NiVpp}$ may indeed target the elusive "true" HSC population within the CD $34^{+} \mathrm{CD} 38^{-} \mathrm{CD}^{+}{ }^{+}$subset. Functional confirmation will require limiting dilution in LTSCID repopulating assays, which is a focus for future studies.

We are cognizant that cell-type-dependent postentry restriction factors may limit the efficiency of NiVpp transduction regardless of how fusogenic we make the F protein. However, the extraordinary specificity of NiVpp, exhibited by the ability to selectively target ephrinB2 ${ }^{+}$cells even in a 1,000-fold excess of ephrinB2-negative cells (Fig. 3), prompted us to examine the transduction efficiency of NiVpp in vivo, especially when NiVpp were administered intravenously and therefore subjected not only to dilution into the blood and tissue volume but also to the problem of hepatic clearance, a critical barrier for in vivo virusbased gene therapy $(23,24,62)$. Interestingly, when VSVpp and NiVpp carrying a luciferase reporter gene were injected intravenously into mice and subsequently subjected to whole-animal and -organ imaging for D-luciferin-induced bioluminescence signals, T5F $\Delta$ N3/wt G NiVpp demonstrated an enhanced signal in the spleen and lungs compared to T5F/wt G NiVpp (Fig. 5B). Significantly, we did not detect a signal in the liver, as observed with VSV-Gpp, with either NiVpp, suggesting that NiVpp could bypass the liver sink. However, in vivo bioluminescence imaging has limited sensitivity, as signals are generally detected only when high local concentrations of cells are transduced (typically $>10^{3}$ to $10^{4}$ ) $(63,64)$. Thus, we performed a sensitive PCR-based biodistribution study to quantify the copy numbers of genomic vector integrants in these tissues (Fig. 5C). This PCR assay confirmed that NiVpp did not transduce the liver to any significant level above background, while VSV-Gpp clearly could.

Rapid clearance and degradation of intravenously administered viral vectors by the liver have long been noted as important obstacles to virus-based gene therapy $(23,24,62)$. Our data suggest that NiVpp can effectively bypass the liver sink and target ephrinB2 ${ }^{+}$cells in selected organs in vivo without the need to modify the intrinsic specificity of the receptor-binding attachment protein (NiV-G). Interestingly, our PCR-based biodistribution studies (Fig. 5C) showed that both normo-fusogenic (T5F/wt $\mathrm{G}$ ) and hyperfusogenic (T5F $\Delta 3 /$ wt G) NiVpp could transduce the spleen and lung with equivalent efficiencies, in contrast to the bioluminescence results (Fig. 5B). Additionally, our biodistribution assay also showed that VSV-Gpp (FG12 vector based) could transduce the lung at the same levels as NiVpp, but bioluminescence signals were clearly lacking in the lungs of VSV-Gpp (FvcF1w vector based)-transduced animals. VSV-Gpp can transduce a wide array of tissues, and thus the lack of detectable bioluminescence signals in the lung is likely a reflection of the limits of the detection methodology as discussed above. However, identification of the specific cell populations infected in the spleen and 
lungs is necessary for future optimization of the NiVpp platform for targeted gene therapy. EphrinB2 is highly expressed on endothelial cells, smooth muscle cells surrounding some arterioles, and neurons $(46,47)$. Unlike ephrinB2, ephrinB3 is expressed mostly in the CNS (48). Our own expression studies on multiple cell types and tissues confirm and extend these findings (Table 1). As mentioned above, these expression patterns are in concordance with the tissues that are targeted in the context of a natural human Nipah virus infection (65). Importantly, Table 1 also shows that endoderm tissues do not express ephrinB2 or -B3. Indeed, of the major organs examined in a large autopsy series, the liver was one of the few organs that exhibited no pathology or presence of any detectable viral antigens (50). The latter observations are consistent with the lack of liver transduction seen with our NiVpp. In the spleen, viral antigen staining can be seen in macrophages and multinucleated giant cells. In the lung, viral antigens are seen most commonly in small blood vessels and, less often, in bronchial epithelial cells and alveolar macrophages. Since intravenous administration of NiVpp does not reflect the natural mode of NiV infection, determining the cell types transduced by NiVpp in the spleen and lung will be an important focus of future studies.

Altogether, our data demonstrate that we can generate hightiter, concentrated $\left(10^{8}\right.$ to $\left.10^{9} \mathrm{IU} / \mathrm{ml}\right)$ stocks of NiVpp that can specifically target ephrinB2- and ephrinB3-positive cells in vitro and in vivo. Although $\mathrm{NiV}$ uses ephrinB3 as an alternate receptor, the affinity of NiV-G for ephrinB3 is less than that for ephrinB2 (19). Nevertheless, ephrinB3 is expressed in regions in the CNS where ephrinB2 is lacking, including the corpus callosum and spinal cord (66). Thus, NiVpp can potentially be used to also target these ephrinB3-positive regions. EphrinB2 has been shown to be upregulated in many types of cancer, including ovarian (67), uterine (68), and colon (69) cancers. In the appropriate context, inhibition of ephrinB2-ephB4 interactions has resulted in inhibition of tumor growth and angiogenesis (70). In some cases, breast cancer stromal cells overexpress ephB4 to attract tumor angiogenic vessels that overexpress ephrinB2 (71). Thus, NiVpp can potentially be used to either target appropriate tumors where overexpression of ephrinB2 has been linked to a poorer prognosis or antagonize ephrinB2 interactions with ephB4 to inhibit tumor angiogenesis (reviewed in references 20 and 21).

Many other viral envelopes have been modified for targeted gene therapy. For many of them, the receptor-binding domain and the fusion domain of the envelope are produced from a single viral env gene. Thus, manipulation to enhance receptor-targeting specificity is more likely to adversely affect the fusion domain of the envelope protein, resulting in low viral titers. For paramyxoviruses, the receptor-binding attachment protein and the fusion protein are produced from two independent viral genes. Mechanistic studies of how receptor binding to the attachment protein leads to allosteric triggering of the fusion protein represent an area of intense study by many labs (reviewed in references 9, 12, 51, 52, 72 , and 73). For the henipaviruses, a large body of work has accumulated regarding the independent determinants of fusogenicity in F and G. Thus, F can be made even more fusogenic by incorporating other mutations that are already well characterized in the literature $(3,27,28,74-76)$. Indeed, even the specificity and fusogenicity of $\mathrm{G}$ itself can be optimized based on published structural and functional data $(5,12,40,41,53,54,77)$. Altogether, this confluence of properties makes NiVpp highly attractive for fur- ther development as targeted gene therapy vectors for in vitro and in vivo applications.

\section{ACKNOWLEDGMENTS}

The stem cell work was supported by California Institute for Regenerative Medicine grant RB2-01571, and the non-stem-cell work was supported by NIH grant AI069317-06. We acknowledge support from the UCLA CFAR Virology Core (p24 determinations) and the Gene and Cellular Therapy Core (human $\mathrm{CD}_{34}{ }^{+}$cells) (NIH grant AI028697), the UCLA AIDS Institute, and the UCLA Council of Bioscience Resources. We also acknowledge support from the Eli and Edythe Broad Center of Regenerative Medicine and the Stem Cell Research Center FACS Core. W.E.L. was supported by the Eli and Edythe Broad Center of Regenerative Medicine and Stem Cell Research by a UCLA Innovation Award. H.K.A.M. was supported by NIH grant RO1 HL097766.

\section{REFERENCES}

1. Mochizuki H, Schwartz JP, Tanaka K, Brady RO, Reiser J. 1998. High-titer human immunodeficiency virus type 1-based vector systems for gene delivery into nondividing cells. J. Virol. 72:8873-8883.

2. Reiser J, Harmison G, Kluepfel-Stahl S, Brady RO, Karlsson S, Schubert M. 1996. Transduction of nondividing cells using pseudotyped defective high-titer HIV type 1 particles. Proc. Natl. Acad. Sci. U. S. A. 93:1526615271.

3. Morizono K, Ku A, Xie Y, Harui A, Kung SK, Roth MD, Lee B, Chen IS. 2010. Redirecting lentiviral vectors pseudotyped with Sindbis virusderived envelope proteins to DC-SIGN by modification of N-linked glycans of envelope proteins. J. Virol. 84:6923-6934.

4. Morizono K, Xie Y, Ringpis GE, Johnson M, Nassanian H, Lee B, Wu L, Chen IS. 2005. Lentiviral vector retargeting to P-glycoprotein on metastatic melanoma through intravenous injection. Nat. Med. 11:346352.

5. Ni Choileain S, Astier AL. 2012. CD46 processing: a means of expression. Immunobiology 217:169-175.

6. Frecha C, Costa C, Negre D, Gauthier E, Russell SJ, Cosset FL, Verhoeyen E. 2008. Stable transduction of quiescent T cells without induction of cycle progression by a novel lentiviral vector pseudotyped with measles virus glycoproteins. Blood 112:4843-4852.

7. Funke S, Maisner A, Muhlebach MD, Koehl U, Grez M, Cattaneo R, Cichutek K, Buchholz CJ. 2008. Targeted cell entry of lentiviral vectors. Mol. Ther. 16:1427-1436.

8. Arce F, Breckpot K, Collins M, Escors D. 2011. Targeting lentiviral vectors for cancer immunotherapy. Curr. Cancer Ther. Rev. 7:248-260.

9. Buchholz CJ, Muhlebach MD, Cichutek K. 2009. Lentiviral vectors with measles virus glycoproteins_-dream team for gene transfer? Trends Biotechnol. 27:259-265.

10. Frecha C, Levy C, Cosset FL, Verhoeyen E. 2010. Advances in the field of lentivector-based transduction of T and B lymphocytes for gene therapy. Mol. Ther. 18:1748-1757.

11. Chang A, Dutch RE. 2012. Paramyxovirus fusion and entry: multiple paths to a common end. Viruses 4:613-636.

12. Lee B, Ataman ZA. 2011. Modes of paramyxovirus fusion: a henipavirus perspective. Trends Microbiol. 19:389-399.

13. Plemper RK, Brindley MA, Iorio RM. 2011. Structural and mechanistic studies of measles virus illuminate paramyxovirus entry. PLoS Pathog. 7:e1002058. doi:10.1371/journal.ppat.1002058.

14. Navaratnarajah CK, Leonard VH, Cattaneo R. 2009. Measles virus glycoprotein complex assembly, receptor attachment, and cell entry. Curr. Top. Microbiol. Immunol. 329:59-76.

15. Anliker B, Abel T, Kneissl S, Hlavaty J, Caputi A, Brynza J, Schneider IC, Munch RC, Petznek H, Kontermann RE, Koehl U, Johnston IC, Keinanen K, Muller UC, Hohenadl C, Monyer H, Cichutek K, Buchholz CJ. 2010. Specific gene transfer to neurons, endothelial cells and hematopoietic progenitors with lentiviral vectors. Nat. Methods 7:929-935.

16. Khetawat D, Broder CC. 2010. A functional henipavirus envelope glycoprotein pseudotyped lentivirus assay system. Virol. J. 7:312.

17. Bonaparte MI, Dimitrov AS, Bossart KN, Crameri G, Mungall BA, Bishop KA, Choudhry V, Dimitrov DS, Wang LF, Eaton BT, Broder CC. 2005. Ephrin-B2 ligand is a functional receptor for Hendra virus and Nipah virus. Proc. Natl. Acad. Sci. U. S. A. 102:10652-10657. 
18. Negrete OA, Levroney EL, Aguilar HC, Bertolotti-Ciarlet A, Nazarian R, Tajyar S, Lee B. 2005. EphrinB2 is the entry receptor for Nipah virus, an emergent deadly paramyxovirus. Nature 436:401-405.

19. Negrete OA, Wolf MC, Aguilar HC, Enterlein S, Wang W, Muhlberger E, Su SV, Bertolotti-Ciarlet A, Flick R, Lee B. 2006. Two key residues in ephrinB3 are critical for its use as an alternative receptor for Nipah virus. PLoS Pathog. 2:e7. doi:10.1371/journal.ppat.0020007.

20. Pasquale EB. 2008. Eph-ephrin bidirectional signaling in physiology and disease. Cell 133:38-52.

21. Pasquale EB. 2010. Eph receptors and ephrins in cancer: bidirectional signalling and beyond. Nat. Rev. Cancer 10:165-180.

22. Ivanova NB, Dimos JT, Schaniel C, Hackney JA, Moore KA, Lemischka IR. 2002. A stem cell molecular signature. Science 298:601-604.

23. Elvevold K, Smedsrod B, Martinez I. 2008. The liver sinusoidal endothelial cell: a cell type of controversial and confusing identity. Am. J. Physiol. Gastrointest. Liver Physiol. 294:G391-G400.

24. Ganesan LP, Mohanty S, Kim J, Clark KR, Robinson JM, Anderson CL. 2011. Rapid and efficient clearance of blood-borne virus by liver sinusoidal endothelium. PLoS Pathog. 7:e1002281. doi:10.1371/journal.ppat .1002281 .

25. Levroney EL, Aguilar HC, Fulcher JA, Kohatsu L, Pace KE, Pang M, Gurney KB, Baum LG, Lee B. 2005. Novel innate immune functions for galectin-1: galectin-1 inhibits cell fusion by Nipah virus envelope glycoproteins and augments dendritic cell secretion of proinflammatory cytokines. J. Immunol. 175:413-420.

26. Wolf MC, Wang Y, Freiberg AN, Aguilar HC, Holbrook MR, Lee B. 2009. A catalytically and genetically optimized beta-lactamase-matrix based assay for sensitive, specific, and higher throughput analysis of native henipavirus entry characteristics. Virol. J. 6:119.

27. Aguilar HC, Matreyek KA, Choi DY, Filone CM, Young S, Lee B. 2007. Polybasic KKR motif in the cytoplasmic tail of Nipah virus fusion protein modulates membrane fusion by inside-out signaling. J. Virol. 81:45204532.

28. Aguilar HC, Matreyek KA, Filone CM, Hashimi ST, Levroney EL, Negrete OA, Bertolotti-Ciarlet A, Choi DY, McHardy I, Fulcher JA, Su SV, Wolf MC, Kohatsu L, Baum LG, Lee B. 2006. N-glycans on Nipah virus fusion protein protect against neutralization but reduce membrane fusion and viral entry. J. Virol. 80:4878-4889.

29. Lois C, Hong EJ, Pease S, Brown EJ, Baltimore D. 2002. Germline transmission and tissue-specific expression of transgenes delivered by lentiviral vectors. Science 295:868-872.

30. Qin XF, An DS, Chen IS, Baltimore D. 2003. Inhibiting HIV-1 infection in human T cells by lentiviral-mediated delivery of small interfering RNA against CCR5. Proc. Natl. Acad. Sci. U. S. A. 100:183-188.

31. Esko JD, Stewart TE, Taylor WH. 1985. Animal cell mutants defective in glycosaminoglycan biosynthesis. Proc. Natl. Acad. Sci. U. S. A. 82:31973201.

32. Damoiseaux R, Sherman SP, Alva JA, Peterson C, Pyle AD. 2009. Integrated chemical genomics reveals modifiers of survival in human embryonic stem cells. Stem Cells 27:533-542.

33. Shimizu S, Hong P, Arumugam B, Pokomo L, Boyer J, Koizumi N, Kittipongdaja P, Chen A, Bristol G, Galic Z, Zack JA, Yang O, Chen IS, Lee B, An DS. 2010. A highly efficient short hairpin RNA potently downregulates CCR5 expression in systemic lymphoid organs in the hu-BLT mouse model. Blood 115:1534-1544.

34. Karumbayaram S, Novitch BG, Patterson M, Umbach JA, Richter L, Lindgren A, Conway AE, Clark AT, Goldman SA, Plath K, WiedauPazos M, Kornblum HI, Lowry WE. 2009. Directed differentiation of human-induced pluripotent stem cells generates active motor neurons. Stem Cells 27:806-811.

35. Van Handel B, Montel-Hagen A, Sasidharan R, Nakano H, Ferrari R, Boogerd CJ, Schredelseker J, Wang Y, Hunter S, Org T, Zhou J, Li X, Pellegrini M, Chen JN, Orkin SH, Kurdistani SK, Evans SM, Nakano A, Mikkola HK. 2012. Scl represses cardiomyogenesis in prospective hemogenic endothelium and endocardium. Cell 150:590-605.

36. Teo AK, Arnold SJ, Trotter MW, Brown S, Ang LT, Chng Z, Robertson EJ, Dunn NR, Vallier L. 2011. Pluripotency factors regulate definitive endoderm specification through eomesodermin. Genes Dev. 25:238-250.

37. Kobayashi M, Iida A, Ueda Y, Hasegawa M. 2003. Pseudotyped lentivirus vectors derived from simian immunodeficiency virus SIVagm with envelope glycoproteins from paramyxovirus. J. Virol. 77:2607-2614.

38. Frecha C, Levy C, Costa C, Negre D, Amirache F, Buckland R, Russell SJ, Cosset FL, Verhoeyen E. 2011. Measles virus glycoprotein- pseudotyped lentiviral vector-mediated gene transfer into quiescent lymphocytes requires binding to both SLAM and CD46 entry receptors. J. Virol. 85:5975-5985.

39. Pernet O, Wang YE, Lee B. 2012. Henipavirus receptor usage and tropism. Curr. Top. Microbiol. Immunol. 359:59-78.

40. Ayllon J, Villar E, Munoz-Barroso I. 2010. Mutations in the ectodomain of Newcastle disease virus fusion protein confer a hemagglutininneuraminidase-independent phenotype. J. Virol. 84:1066-1075.

41. Rawling J, Garcia-Barreno B, Melero JA. 2008. Insertion of the two cleavage sites of the respiratory syncytial virus fusion protein in Sendai virus fusion protein leads to enhanced cell-cell fusion and a decreased dependency on the HN attachment protein for activity. J. Virol. 82:59865998.

42. Sergel TA, McGinnes LW, Morrison TG. 2000. A single amino acid change in the Newcastle disease virus fusion protein alters the requirement for $\mathrm{HN}$ protein in fusion. J. Virol. 74:5101-5107.

43. Seth S, Vincent A, Compans RW. 2003. Mutations in the cytoplasmic domain of a paramyxovirus fusion glycoprotein rescue syncytium formation and eliminate the hemagglutinin-neuraminidase protein requirement for membrane fusion. J. Virol. 77:167-178.

44. Geisbert TW, Feldmann H, Broder CC. 2012. Animal challenge models of henipavirus infection and pathogenesis. Curr. Top. Microbiol. Immunol. 359:153-177.

45. Majeti R, Park CY, Weissman IL. 2007. Identification of a hierarchy of multipotent hematopoietic progenitors in human cord blood. Cell Stem Cell 1:635-645.

46. Gale NW, Baluk P, Pan L, Kwan M, Holash J, DeChiara TM, McDonald DM, Yancopoulos GD. 2001. Ephrin-B2 selectively marks arterial vessels and neovascularization sites in the adult, with expression in both endothelial and smooth-muscle cells. Dev. Biol. 230:151-160.

47. Shin D, Garcia-Cardena G, Hayashi S, Gerety S, Asahara T, Stavrakis G, Isner J, Folkman J, Gimbrone MA, Jr, Anderson DJ. 2001. Expression of ephrinB2 identifies a stable genetic difference between arterial and venous vascular smooth muscle as well as endothelial cells, and marks subsets of microvessels at sites of adult neovascularization. Dev. Biol. 230:139-150.

48. Flenniken AM, Gale NW, Yancopoulos GD, Wilkinson DG. 1996. Distinct and overlapping expression patterns of ligands for Eph-related receptor tyrosine kinases during mouse embryogenesis. Dev. Biol. 179: 382-401.

49. Maisner A, Neufeld J, Weingartl H. 2009. Organ- and endotheliotropism of Nipah virus infections in vivo and in vitro. Thromb. Haemost. 102: 1014-1023.

50. Wong KT, Shieh WJ, Kumar S, Norain K, Abdullah W, Guarner J, Goldsmith CS, Chua KB, Lam SK, Tan CT, Goh KJ, Chong HT, Jusoh R, Rollin PE, Ksiazek TG, Zaki SR. 2002. Nipah virus infection: pathology and pathogenesis of an emerging paramyxoviral zoonosis. Am. J. Pathol. 161:2153-2167.

51. Galanis E. 2010. Therapeutic potential of oncolytic measles virus: promises and challenges. Clin. Pharmacol. Ther. 88:620-625.

52. Munch RC, Muhlebach MD, Schaser T, Kneissl S, Jost C, Pluckthun A, Cichutek K, Buchholz CJ. 2011. DARPins: an efficient targeting domain for lentiviral vectors. Mol. Ther. 19:686-693.

53. Levy C, Amirache F, Costa C, Frecha C, Muller CP, Kweder H, Buckland R, Cosset FL, Verhoeyen E. 2012. Lentiviral vectors displaying modified measles virus gp overcome pre-existing immunity in in vivo-like transduction of human T and B cells. Mol. Ther. 20:1699-1712.

54. Luby SP, Gurley ES. 2012. Epidemiology of henipavirus disease in humans. Curr. Top. Microbiol. Immunol. 359:25-40.

55. Graf T, Stadtfeld M. 2008. Heterogeneity of embryonic and adult stem cells. Cell Stem Cell 3:480-483.

56. Hough SR, Laslett AL, Grimmond SB, Kolle G, Pera MF. 2009. A continuum of cell states spans pluripotency and lineage commitment in human embryonic stem cells. PLoS One 4:e7708. doi:10.1371/journal .pone.0007708.

57. Hayashi K, Lopes SM, Tang F, Surani MA. 2008. Dynamic equilibrium and heterogeneity of mouse pluripotent stem cells with distinct functional and epigenetic states. Cell Stem Cell 3:391-401.

58. Poliakov A, Cotrina M, Wilkinson DG. 2004. Diverse roles of eph receptors and ephrins in the regulation of cell migration and tissue assembly. Dev. Cell 7:465-480.

59. Sela-Donenfeld D, Wilkinson DG. 2005. Eph receptors: two ways to sharpen boundaries. Curr. Biol. 15:R210-R212.

60. Baum CM, Weissman IL, Tsukamoto AS, Buckle AM, Peault B. 1992. 
Isolation of a candidate human hematopoietic stem-cell population. Proc. Natl. Acad. Sci. U. S. A. 89:2804-2808.

61. Craig W, Kay R, Cutler RL, Lansdorp PM. 1993. Expression of Thy-1 on human hematopoietic progenitor cells. J. Exp. Med. 177:1331-1342.

62. Zhang L, Dailey PJ, Gettie A, Blanchard J, Ho DD. 2002. The liver is a major organ for clearing simian immunodeficiency virus in rhesus monkeys. J. Virol. 76:5271-5273.

63. Contag CH, Ross BD. 2002. It's not just about anatomy: in vivo bioluminescence imaging as an eyepiece into biology. J. Magn. Reson. Imaging $16: 378-387$.

64. Shah K, Jacobs A, Breakefield XO, Weissleder R. 2004. Molecular imaging of gene therapy for cancer. Gene Ther. 11:1175-1187.

65. Wong KT, Tan CT. 2012. Clinical and pathological manifestations of human henipavirus infection. Curr. Top. Microbiol. Immunol. 359:95104.

66. Liebl DJ, Morris CJ, Henkemeyer M, Parada LF. 2003. mRNA expression of ephrins and Eph receptor tyrosine kinases in the neonatal and adult mouse central nervous system. J. Neurosci. Res. 71:7-22.

67. Alam SM, Fujimoto J, Jahan I, Sato E, Tamaya T. 2008. Coexpression of EphB4 and ephrinB2 in tumour advancement of ovarian cancers. Br. J. Cancer 98:845-851.

68. Alam SM, Fujimoto J, Jahan I, Sato E, Tamaya T. 2007. Overexpression of ephrinB2 and EphB4 in tumor advancement of uterine endometrial cancers. Ann. Oncol. 18:485-490.

69. Liu W, Ahmad SA, Jung YD, Reinmuth N, Fan F, Bucana CD, Ellis LM. 2002. Coexpression of ephrin-Bs and their receptors in colon carcinoma. Cancer 94:934-939.
70. Kertesz N, Krasnoperov V, Reddy R, Leshanski L, Kumar SR, Zozulya S, Gill PS. 2006. The soluble extracellular domain of EphB4 (sEphB4) antagonizes EphB4-EphrinB2 interaction, modulates angiogenesis, and inhibits tumor growth. Blood 107:2330-2338.

71. Noren NK, Lu M, Freeman AL, Koolpe M, Pasquale EB. 2004. Interplay between EphB4 on tumor cells and vascular ephrin-B2 regulates tumor growth. Proc. Natl. Acad. Sci. U. S. A. 101:5583-5588.

72. Blechacz B, Russell SJ. 2008. Measles virus as an oncolytic vector platform. Curr. Gene Ther. 8:162-175.

73. Russell SJ, Peng KW. 2009. Measles virus for cancer therapy. Curr. Top. Microbiol. Immunol. 330:213-241.

74. Aguilar HC, Aspericueta V, Robinson LR, Aanensen KE, Lee B. 2010. A quantitative and kinetic fusion protein-triggering assay can discern distinct steps in the Nipah virus membrane fusion cascade. J. Virol. 84:80338041 .

75. Morizono K, Xie Y, Helguera G, Daniels TR, Lane TF, Penichet ML, Chen IS. 2009. A versatile targeting system with lentiviral vectors bearing the biotin-adaptor peptide. J. Gene Med. 11:655-663.

76. Wong LF, Goodhead L, Prat C, Mitrophanous KA, Kingsman SM, Mazarakis ND. 2006. Lentivirus-mediated gene transfer to the central nervous system: therapeutic and research applications. Hum. Gene Ther. $17: 1-9$.

77. Xu K, Rajashankar KR, Chan YP, Himanen JP, Broder CC, Nikolov DB. 2008. Host cell recognition by the henipaviruses: crystal structures of the Nipah G attachment glycoprotein and its complex with ephrin-B3. Proc. Natl. Acad. Sci. U. S. A. 105:9953-9958. 